\title{
Bilayered silk/silk-nanoCaP scaffolds for osteochondral tissue engineering: In vitro and in vivo assessment of biological performance
}

\author{
Le-Ping Yan ${ }^{\mathrm{a}, \mathrm{b}}$, Joana Silva-Correia ${ }^{\mathrm{a}, \mathrm{b}}$, Mariana B. Oliveira ${ }^{\mathrm{a}, \mathrm{b}}$, Carlos Vilela ${ }^{\mathrm{a}, \mathrm{b}, \mathrm{c}, \mathrm{d}}$, Hélder Pereira ${ }^{\mathrm{a}, \mathrm{b}, \mathrm{e}, \mathrm{f}}$, \\ Rui A. Sousa ${ }^{a, b}$, João F. Mano ${ }^{a, b}$, Ana L. Oliveira ${ }^{a, b, g}$, Joaquim M. Oliveira ${ }^{a, b, *}$, Rui L. Reis ${ }^{a, b}$ \\ a 3B's Research Group-Biomaterials, Biodegradables and Biomimetics, University of Minho, Headquarters of the European Institute of Excellence on Tissue Engineering \\ and Regenerative Medicine, AvePark, S. Cláudio de Barco, 4806-909 Taipas, Guimarães, Portugal \\ b ICVS/3B's-PT Government Associate Laboratory, Braga/Guimarães, Portugal \\ ${ }^{\mathrm{c}}$ Life and Health Sciences Research Institute (ICVS), School of Health Sciences, University of Minho, Portugal \\ d Orthopedic Department, Centro Hospitalar do Alto Ave, Guimarães, Portugal \\ e Saúde Atlântica Sports Center-FC Porto Stadium, Minho University and Porto University Research Center, Porto, Portugal \\ ${ }^{\mathrm{f}}$ Orthopedic Department, Centro Hospitalar Póvoa de Varzim, Vila do Conde, Portugal \\ ${ }^{\mathrm{g}}$ CBQF-Center for Biotechnology and Fine Chemistry, School of Biotechnology, Portuguese Catholic University, Porto 4200-072, Portugal
}

\section{A R T I C L E I N F O}

Article history:

Received 9 May 2014

Received in revised form 12 September 2014

Accepted 15 October 2014

Available online 23 October 2014

\section{Keywords:}

Bilayered scaffold

Silk fibroin

Calcium phosphate

Osteochondral regeneration

Nanocomposite

\begin{abstract}
A B S T R A C T
Novel porous bilayered scaffolds, fully integrating a silk fibroin (SF) layer and a silk-nano calcium phosphate (silk-nanoCaP) layer for osteochondral defect $(\mathrm{OCD})$ regeneration, were developed. Homogeneous porosity distribution was achieved in the scaffolds, with calcium phosphate phase only retained in the silk-nanoCaP layer. The scaffold presented compressive moduli of $0.4 \mathrm{MPa}$ in the wet state. Rabbit bone marrow mesenchymal stromal cells (RBMSCs) were cultured on the scaffolds, and good adhesion and proliferation were observed. The silk-nanoCaP layer showed a higher alkaline phosphatase level than the silk layer in osteogenic conditions. Subcutaneous implantation in rabbits demonstrated weak inflammation. In a rabbit knee critical size OCD model, the scaffolds firmly integrated into the host tissue. Histological and immunohistochemical analysis showed that collagen II positive cartilage and glycosaminoglycan regeneration presented in the silk layer, and de novo bone ingrowths and vessel formation were observed in the silk-nanoCaP layer. These bilayered scaffolds can therefore be promising candidates for OCD regeneration.
\end{abstract}

(c) 2014 Acta Materialia Inc. Published by Elsevier Ltd. All rights reserved.

\section{Introduction}

Osteochondral defects (OCDs) are a common problem in joints $[1,2]$, and include defects both in the articular cartilage and the underlying subchondral bone. Cartilage defects are normally irreversible, and would likely induce OCDs. Diseases arising from the subchondral bone, such as osteochondritis dissecans and osteonecrosis, can also cause OCDs [3]. Osteochondral fracture constitutes an important cause of OCDs. Besides the knee, OCDs can also be found in the ankle, specifically in the talus [4,5]. OCDs will induce persistent symptoms of pain and limited motion of the joint. Every

\footnotetext{
* Corresponding author at: 3B's Research Group-Biomaterials, Biodegradables and Biomimetics, University of Minho, Headquarters of the European Institute of Excellence on Tissue Engineering and Regenerative Medicine, AvePark, S. Cláudio de Barco, 4806-909 Taipas, Guimarães, Portugal. Tel.: +351 253 510908; fax: +351 253 510909.

E-mail address: miguel.oliveira@dep.uminho.pt (J.M. Oliveira).
}

year, the healthcare cost for OCDs is about $\$ 95$ billion in the United States alone [6].

Several techniques are currently used clinically to treat OCDs, including arthroscopic debridement, microfracture, osteochondral (OC) autograft transplantation and autologous chondrocyte implantation [7]. These approaches are not ideal, since they are palliative or induce donor site morbidity. OC tissue engineering emerged as a promising alternative strategy for OCD regeneration [8-11]. It has been reported that the cartilage cannot spontaneously repair without support from healthy subchondral bone [12]. Therefore, the rehabilitation of the subchondral bone should be performed simultaneously with the reconstruction of the cartilage layer.

The development of bioactive bilayered scaffolds for OCD regeneration has been considered a desirable strategy [13-16]. Growth factors have been introduced into the bilayered scaffolds to enhance cartilage repair $[15,16]$. Spatially controlled dual-growth factors or gene-release systems have also been developed and both 
the repair of cartilage and subchondral bone layers were observed $[17,18]$. On the other hand, the incorporation of osteoconductive materials into bilayered scaffolds was able to promote the fast subchondral bone formation $[19,20]$. Some commercial bilayered scaffolds, e.g. Trufit ${ }^{\circledR}$ and MaioRegen ${ }^{\circledR}$, have been applied clinically in acellular strategies [21-23]. Kon et al. [21] showed that multilayer collagen/nanohydroxyapatite scaffolds promoted bone and cartilage tissue restoration. Nevertheless, improvement in the mechanical properties/stability of bilayered scaffold and optimization of the incorporation of bioactive factors in the scaffolds are still big challenges $[17,24,25]$. Other problems are related to achieving a good interface between the different layers [26].

Natural biopolymers have been used for tissue regeneration and presented superior in vitro and in vivo compatibility $[27,28]$. Among natural polymers, silk fibroin (SF) exhibits tunable mechanical properties [29], and thus has been finding a range of applications in tissue engineering [30-34]. Calcium phosphate (CaP)-based materials have been found to show outstanding osteoconductivity in bone regeneration [35,36]. Development of polymer/CaP composite scaffolds is a promising strategy to overcome the low elasticity of CaP $[20,21]$. Previously, robust SF and silk/nano-sized CaP (silk-nanoCaP) scaffolds have been produced $[37,38]$. These scaffolds were able to promote in vivo new bone formation [39]. Based on these promising outcomes, our group recently developed a novel bilayered scaffold composed of a silk layer and a silk-nanoCaP layer for OCD regeneration and characterized some preliminary properties of the scaffolds [40].

In this study, we aim to comprehensively understand the physicochemical properties of the bilayered scaffolds and evaluate their biological performance for OCD regeneration. The composition and structure of the scaffold were evaluated by Fourier transform infrared spectroscopy (FTIR), micro-computed tomography (micro-CT) and energy-dispersive X-ray spectrometry. Both dynamic and static mechanical properties were analyzed. Cytocompatibility was evaluated by studying the viability and proliferation of rabbit bone marrow mesenchymal stromal cells (RBMSCs) in the scaffolds. Osteogenic differentiation of the RBMSCs in the scaffold was also examined. The bilayered scaffolds were implanted both subcutaneously and in critical size OCDs of the rabbit knee. The regeneration of osteochondral tissues in these explants were characterized by micro-CT, and by histological and immunohistochemical staining, respectively.

\section{Materials and methods}

\subsection{Materials and reagents}

Bombyx mori cocoons were supplied by the Portuguese Association of Parents and Friends of Mentally Disabled Citizens (APPACDM, Castelo Branco, Portugal). The other materials and reagents were purchased from Sigma-Aldrich (St Louis, MO, USA) unless mentioned otherwise.

\subsection{Preparation of the bilayered scaffolds}

The concentrated aqueous SF solution was obtained via a previously reported procedure [37]. Regarding the preparation of the bilayered scaffolds, silk-nanoCaP scaffolds were first prepared [38]. Briefly, calcium chloride solution $\left(6 \mathrm{~mol}^{-1}\right)$ and ammonia dibasic phosphate solution $\left(3.6 \mathrm{~mol}^{-1}\right)$ of the same volume were sequentially added to the $16 \mathrm{wt} . \%$ SF solution, forming the nano$\mathrm{CaP}$ particles in the silk solution. The amount of CaP introduced was fixed at $16 \mathrm{wt} . \%(\mathrm{CaP} / \mathrm{silk}, \mathrm{w} / \mathrm{w})$. The scaffolds were prepared by addition of sodium chloride particles into the suspension in a silicon mold. The mold was dried for 2 days, and then immersed in distilled water overnight. During the following day, the silknanoCaP scaffolds were cut into pieces after removal from the molds. Each piece of scaffold was placed in the bottom of a new silicon mold and $300 \mu \mathrm{l}$ of $16 \mathrm{wt}$.\% silk solution was added on top of these scaffolds. Then, $600 \mathrm{mg}$ of sodium chloride particles were added to the silk solution [38]. After drying and salt-leaching processes, the final scaffolds were obtained by lyophilization in a freeze drier (CRYODOS-80; Telstar, Barcelona, Spain). As controls, pure silk scaffolds and silk-nanoCaP scaffolds were also prepared. The pure silk scaffolds, the silk-nanoCaP scaffolds and the bilayered scaffolds are abbreviated as S16, SC16 and bilayered, respectively.

\subsection{Physicochemical characterization of the bilayered scaffolds}

\subsubsection{Chemical analysis of the bilayered scaffolds}

The chemical composition and structural conformation of the bilayered scaffolds were analyzed by a Fourier transform infrared spectroscopy (FTIR) under an attenuated total reflectance (ATR) model (IRPrestige-21, Shimadzu, Kyoto, Japan) [39]. At least three specimens were used for each layer.

The CaP content in the silk-nanoCaP layer was evaluated by thermogravimetric analysis (TGA) [38]. The organic phase was degraded by heating the specimen in the TGA instrument (TGA Q500; TA Instruments, DE, USA). The Ca/P atomic ratio of the ash obtained after the TGA assay was studied by an energy-dispersive $\mathrm{X}$-ray detector (EDX). At least three specimens were used for both assays.

\subsubsection{Microstructure evaluation of the bilayered scaffolds}

The morphology of the scaffold was observed by scanning electron microscopy (SEM) (Nova NanoSEM 200; FEI, Hillsboro, OR, USA). Before the observation, the scaffolds were coated with one layer of $\mathrm{Au} / \mathrm{Pd}(\mathrm{SC502-314B)}$ in a coater (E6700; Quorum Technologies, East Grinstead, UK). Elemental analysis was performed in four zones around the interface area by an EDX setup installed in the SEM. Three independent areas were selected in each zone, and each scanned area was $100 \mu \mathrm{m} \times 100 \mu \mathrm{m}$.

Micro-CT was used to qualitatively and quantitatively evaluate the porosity and the CaP distribution profile in the bilayered scaffolds. The scanning of the scaffolds was conducted under $61 \mathrm{keV}$ and $163 \mu \mathrm{A}$ in the micro-CT (1072 scanner; SkyScan, Kontich, Belgium). Both the diameter and the height of the scaffolds were $8 \mathrm{~mm}$ (silk layer: $3 \mathrm{~mm}$ in height; silk-nanoCaP layer: $5 \mathrm{~mm}$ in height). The integration time was fixed at $1.3 \mathrm{~s}$ and the pixel resolution was $9.4 \mu \mathrm{m}$. Qualitative visualization of the 3-D morphology and the different phases in the bilayered scaffolds were performed using CTvox software (Skyscan). The porosity and CaP content distribution profiles were processed in standardized software (CT Analyser, version 1.5., Skyscan) [38]. Five scaffolds were used for the qualitative and quantitative microstructure evaluation.

\subsubsection{Mechanical tests of the scaffolds}

The wet status compressive test of the bilayered scaffolds was performed in a universal testing machine (Instron 4505; Instron, Norwood, MA, USA). The diameter and the height of the scaffolds were 6 and $5 \mathrm{~mm}$, respectively (silk layer: $2 \mathrm{~mm}$ in height; silknanoCaP layer: $3 \mathrm{~mm}$ in height). Before the test, the samples were first hydrated in phosphate buffer saline solution (PBS) overnight at $37^{\circ} \mathrm{C}$. After removing the liquid with a tissue, the samples were tested using a previously reported protocol [39]. S16 and SC16 were used as controls ( $5 \mathrm{~mm}$ in height, $6 \mathrm{~mm}$ in diameter). For each test, six specimens of each group were screened.

Dynamic mechanical analysis (DMA) was also conducted to study the viscoelastic properties of the bilayered scaffolds. The sizes of the scaffolds were the same as for the compressive test. 
The scaffolds were tested in a DMA instrument (TRITEC8000B DMA; Triton Technology, Lincolnshire, UK) [38]. Five samples of each group were tested.

\subsection{In vitro degradation}

The stability of the bilayered scaffolds was evaluated by enzymatic degradation test. Protease XIV solution $\left(1 \mathrm{mg} \mathrm{l}^{-1}\right)$ was prepared by dissolving the enzyme in PBS. The initial dry weight of the scaffold was measured, and then the scaffolds were hydrated in PBS at $37^{\circ} \mathrm{C}$ for $3 \mathrm{~h}$, followed by immersion in $5 \mathrm{ml}$ of protease solution. The scaffolds were the same size as those used for the compressive test. The enzyme solution was changed every $24 \mathrm{~h}$. The specimens were removed from the degradation solution at the end of $0.5,1,2,3,5$ and 7 days. The dry weight of the degraded specimen was measured after drying the sample at $70^{\circ} \mathrm{C}$ overnight. The weight loss ratio was obtained using the following equation:

weight loss ratio $=\left[\frac{\left(m_{i}-m_{d, t}\right)}{\left(m_{i}\right)}\right] \times 100 \%$

where $m_{i}$ is the initial dry weight of the sample, and $m_{d, t}$ is the dry weight of the degraded sample at each time point. S16 and SC16 were used as controls. Five specimens per group were used for each time point.

\subsection{In vitro cell studies}

\subsubsection{Isolation, expansion and seeding of the RBMSCs}

The RBMSCs were isolated from male New Zealand White rabbits (Charles River, Senneville, Quebec, Canada). The maintenance and usage of animals were approved by the Ethics Committee of the University of Minho. The 9 week old rabbits were killed by injecting an overdose of anesthetic. The femurs were first separated from the hind legs, followed by removing the epiphyseal heads and subsequently flushing out the bone marrow plug by using alphaminimum essential medium ( $\alpha$-MEM) $\left(\right.$ Gibco $^{\circledR}$; Life Technologies, Carlsbad, CA, USA). The $\alpha$-MEM was supplemented with $10 \%$ fetal bovine serum, and $1 \%$ antibiotic-antimycotic liquid prepared with 10,000 units $\mathrm{ml}^{-1}$ penicillin $\mathrm{G}$ sodium, $10,000 \mu \mathrm{g} \mathrm{ml}^{-1}$ streptomycin sulfate and $25 \mu \mathrm{g} \mathrm{ml}^{-1}$ amphotericin B as Fungizone ${ }^{\circledR}$ in $0.85 \%$ saline (Life Technologies, Carlsbad, CA, USA). The isolated RBMSCs were cultured in cell culture flasks at $37^{\circ} \mathrm{C}$ in an incubator with $5 \% \mathrm{CO}_{2}$ atmosphere (MCO-18AIC (UV), Sanyo, Osaka, Japan). The medium was changed for the first time after 4 days, and then changed every 2 days until the cells reached $\sim 90 \%$ confluence. The cells were then expanded until passage 2 before seeding in the scaffolds. All the scaffolds were sterilized with ethylene oxide (ETO).

For the cell seeding, bilayered scaffolds $6 \mathrm{~mm}$ in diameter and $5 \mathrm{~mm}$ in height were used (silk layer: $2 \mathrm{~mm}$ in height; silk-nanoCaP layer: $3 \mathrm{~mm}$ in height). S16 and SC16 (6 mm in diameter and $2 \mathrm{~mm}$ in height) were seeded with cells and used as controls for osteogenic differentiation. Before the cell seeding, the scaffolds were hydrated in $\alpha$-MEM overnight in the $\mathrm{CO}_{2}$ incubator. Afterwards, the scaffolds were removed from the medium and placed into a 24-well suspension cell culture plate (Cell star; Greiner Bio-One, Kremsmuenster, Austria). RBMSCs of passage 2 were detached from the flasks and a new cell suspension with a cell density of $5 \times 10^{6} \mathrm{ml}^{-1}$ was prepared (P3). The cells were seeded onto the surface of the scaffolds, and then the scaffolds with cells were kept in the $\mathrm{CO}_{2}$ incubator. After $3 \mathrm{~h}$, the constructs were transferred to a new 24-well suspension culture plate and each construct was supplemented with $2 \mathrm{ml}$ of $\alpha$-MEM. The culture medium was refreshed every 2 or 3 days.

\subsubsection{Viability, attachment, proliferation and differentiation of the RBMSCS}

For the cell viability assay, 100,000 cells were seeded onto the bilayered scaffolds and cultured in basal condition. The live/dead numbers of seeded cells were analyzed by Calcein AM and propidium iodide (Molecular Probes ${ }^{\circledR}$; Life Technologies, Carlsbad, CA, USA) staining after culturing for 3 days. First, each construct was washed with PBS, and then transferred into $1 \mathrm{ml}$ PBS supplemented with $1 \mu \mathrm{g}$ calcein AM and $2 \mu \mathrm{g}$ propidium iodide, for $10 \mathrm{~min}$. The samples were observed in a transmitted and reflected light microscope with apotome 2 (Axio Imager Z1 m; Zeiss, Jena, Germany) after rinsing twice wirh PBS. By using the accompanying software Zen, a Z-stack function was used to combine images at different depths into one final image.

The quantitative cell viability of the constructs was screened by a 3-(4,5-dimethylthiazol-2-yl)-5-(3-carboxymethoxyphenyl)-2-(4sulfophenyl)-2H-tetrazolium) assay (MTS) using the CellTiter $96^{\circledR}$ AQueous One Solution Cell Proliferation Assay Kit (Promega, Fitchburg, WI, USA), after culture for 1, 3 and 7 days. The MTS assay followed the manufacturer's instruction. After $3 \mathrm{~h}$ of reaction with cells, $100 \mu \mathrm{l}$ MTS solution was transferred into a 96-well cell culture plate and read in a microplate reader (Synergy HT; Bio-Tek, VT, USA) at $490 \mathrm{~nm}$. The scaffolds without cells were used as control.

The cells' attachment on the scaffolds in basal condition was observed by SEM, after culturing for 7 days. Before the observation, the constructs were harvested from the medium and rinsed by PBS, followed by immersion in $10 \%$ formalin solution for at least 1 day. The fixed constructs were dehydrated by immersion in a series of aqueous ethanol solutions, with a gradually increasing concentration of ethanol (from 30\% to 100\%). The surface of the constructs were coated by $\mathrm{Au} / \mathrm{Pd}$ and observed by SEM.

For the cell proliferation and osteogenic differentiation assay, 200,000 cells were seeded onto the bilayered scaffolds. The following day, the constructs were cultured in basal medium ( $\alpha$-MEM) or osteogenesis medium, respectively. The osteogenic medium was based on the $\alpha$-MEM, and supplemented with $10 \mathrm{mmol} \mathrm{l}^{-1} \mathrm{~b}$-glycerophosphate, $50 \mu \mathrm{g} \mathrm{ml}^{-1}$ ascorbic acid (Wako Pure Chemicals, Tokyo, Japan) and $10^{-8} \mathrm{~mol} \mathrm{l}^{-1}$ dexamethasone. The constructs were harvested after culturing for 7 and 14 days. At the end of each time point, the silk layer and the silk-nanoCaP layer were separated by a blade, and each part was placed into $1 \mathrm{ml}$ ultrapure water in a $1.5 \mathrm{ml}$ centrifuge tube after rinsing in PBS. The silk layers cultured in basal or osteogenic conditions were abbreviated as Cart.Basal or Cart.Osteo, respectively. The silk-nanoCaP layer cultured in basal or osteogenic conditions were abbreviated as Bone.Basal or Bone.Osteo, respectively. S16 and SC16 were seeded with 100,000 cells per scaffold. The quantification of the doublestranded DNA (dsDNA) was performed by using a Quant-IT PicoGreen dsDNA Assay Kit 2000 assay (Life Technologies, Carlsbad, CA, USA) according to the manufacturer's instructions. The fluorescence intensities of the samples were recorded in a microplate reader [14]. The same lysates for DNA assay were also used for alkaline phosphatase (ALP) activity quantification [14]. The ALP activity of the samples was normalized by their corresponding DNA contents. The DNA contents or ALP activities of the bilayered scaffolds were obtained by combining the DNA contents or ALP activities of the corresponding silk layer and silknanoCaP layer.

\subsection{In vivo implantation of the bilayered scaffolds}

In order to evaluate the in vivo biocompatibility and OCD regeneration potential of the bilayered scaffolds, the scaffolds were subcutaneously implanted in the back and the knee OCD of male New Zealand White rabbits, respectively. The bilayered scaffolds $6 \mathrm{~mm}$ 
in diameter and $8 \mathrm{~mm}$ in height (silk layer: $3 \mathrm{~mm}$; silk-nanoCaP: $5 \mathrm{~mm}$ ) were used for the subcutaneous implantation. Additionally, the bilayered scaffolds $5 \mathrm{~mm}$ in diameter and $5 \mathrm{~mm}$ in height (silk layer: $2 \mathrm{~mm}$; silk-nanoCaP: $3 \mathrm{~mm}$ ) were implanted in the OCD. All the rabbits for the in vivo studies were of 9-11 weeks old, with an average weight of $2.4 \mathrm{~kg}$ at the time of implantation. The scaffolds were sterilized with ETO.

For the subcutaneous implantation, six bilayered scaffolds were implanted into three rabbits ( 2 pieces/rabbit). In each rabbit, two skin incisions were made below the ears in the back (one on the left and the other on the right), each $\sim 2 \mathrm{~cm}$ length. The scaffolds were subcutaneously implanted into each pocket. After 4 weeks, the rabbits were killed by injecting an overdose of anesthetic and the implanted scaffolds were retrieved. The explants were fixed in $10 \%$ formalin, and then dehydrated through graded ethanol, and finally embedded in paraffin. Sections were prepared by cutting the specimen into sections $5 \mu \mathrm{m}$ thick using a microtome (Spencer 820, American Optical Company, NY, USA). The obtained sections were stained with hematoxylin and eosin (H\&E). The dehydrated explants were also coated with $\mathrm{Au} / \mathrm{Pd}$ and observed by SEM.

Regarding the implantation in critical size OCDs $(4.5 \mathrm{~mm}$ in diameter and $5 \mathrm{~mm}$ in depth), nine bilayered scaffolds were implanted into three rabbits (3 pieces/rabbit). The rabbits were anesthetized and the hair in the knee joints of the hind legs was cut. Two OCDs ( $4.5 \mathrm{~mm}$ in diameter and $5 \mathrm{~mm}$ in depth) were created in each femur using a Brace manual drill, one located between the lateral and the medial condyle, the other in the opposite site of the patellar. The bilayered scaffolds were implanted into the defects by press fitting. In each rabbit, one defect located between the lateral and the medial condyle was empty and was used as control. Four weeks post-operation, the rabbits were killed and the knees were excised. Three explants were fixed by $10 \%$ formalin and then immersed in paraffin after dehydration. Slides were prepared and H\&E, Masson's trichrome and Safranin O stainings were performed.

\subsection{Immunohistochemical staining of the explants}

Mouse anti-rabbit collagen II alpha 1 (Acris Antibodies GmbH, Herford, Germany) and biotinylated Sambucus nigra (Elderberry) bark lectin (SNA-lectin; Vector Laboratories, Burlingame, CA, USA) were used for the immunohistochemical staining of the explants following the protocol provided by the supplier. After deparaffinization and rehydration of the specimen slides, the antigens were retrieved in $0.01 \mathrm{~mol} \mathrm{l}^{-1}$ sodium citrate buffer solution at $95{ }^{\circ} \mathrm{C}$ for $20 \mathrm{~min}$ ( $\mathrm{pH} \mathrm{6.0)}$ ), and then the endogenous peroxidases were inactivated by using $3 \%(\mathrm{v} / \mathrm{v})$ hydrogen peroxide solution. For collagen II immunohistochemical staining, the specimen slides were subsequently incubated overnight at $4{ }^{\circ} \mathrm{C}$ after addition of the primary antibodies. Then, the slides were incubated with secondary antibody donkey anti-mouse Alexa Fluor 594 (Molecular Probes, Eugene, OR, USA). The nuclei of the cells in the slides were counterstained with 4',6-diamidino-2-phynylindole (DAPI) solution $\left(1 \mu \mathrm{g} \mathrm{ml}^{-1}\right.$ in PBS) for $10 \mathrm{~min}$. Finally, the slides were mounted and observed in a fluorescence microscope. The SNA-lectin immunohistochemical analysis was performed according to the streptavidin-biotin peroxidase complex system (UltraVision Large Volume Detection System Anti-Polyvalent, HRP; LabVision Corporation, Fremont, CA, USA). After inactivation of the endogenous peroxidases and soaking in PBS, the slides were incubated in protein blocking solution for 10 min followed by incubation with the primary antibody SNA-lectin for $1 \mathrm{~h}$ and at room temperature. Sections were then sequentially washed with PBS and incubated with the streptavidin-peroxidase complex for $10 \mathrm{~min}$. The immune reaction was visualized by $3,3^{\prime}$-diamonobenzidine
(DAB; LabVision Corporation, Fremont, CA, USA) as a chromogen. All sections were counterstained with Gill-2 hematoxylin (Merck, Germany). For preparing the negative controls, the primary antibody was omitted. The histological sections were then observed using a light microscope.

\subsection{Micro-CT analysis of the explants}

Three explants were used for micro-CT observation in the wet state, under $100 \mathrm{keV}$ and $98 \mu \mathrm{A}$. The explants were loaded with Parafilm ${ }^{\circledR}$ during the scanning to avoid evaporation of liquid. The integration time was fixed at $1.3 \mathrm{~s}$ and the pixel resolution was $19.13 \mu \mathrm{m}$. The specimens were first scanned and the data sets were processed as mentioned above (Section 2.3.2). In each specimen, a cylindrical model region (height: $4 \mathrm{~mm}$; diameter: $4 \mathrm{~mm}$ ) was used for the evaluation of porosity and CaP distribution. The top $2 \mathrm{~mm}$ region in the cylindrical model region was considered as cartilage domain in defect controls or as silk layer in defects implanted with scaffolds, and the next $2 \mathrm{~mm}$ region down was considered as subchondral bone domain in defect controls or as silk-nanoCaP layer in defects implanted with scaffolds.

\subsection{Statistical analysis}

The data were presented by mean \pm standard deviation (SD). The results were evaluated by one-way analysis of variance (ANOVA). The means of each group were compared by Tukey's test, and $P<0.05$ was considered statistically significant. Three independent experiments were performed for the cell viability assay, the proliferation and differentiation studies, and at least three samples were analyzed for each time point in every experiment.

\section{Results}

\subsection{Chemical composition and structural conformation of the bilayered scaffolds}

The SF conformation and chemical composition in the bilayered scaffolds were studied by ATR-FTIR. As shown in Fig. 1, the SF in both layers displayed the same strong absorbance peaks at 1627 and $1520 \mathrm{~cm}^{-1}$, which are characteristic peaks for $\beta$-sheet conformation [30]. It was noticed that both layers presented shoulder peaks $\sim 1650 \mathrm{~cm}^{-1}$ corresponding to amorphous or silk-I

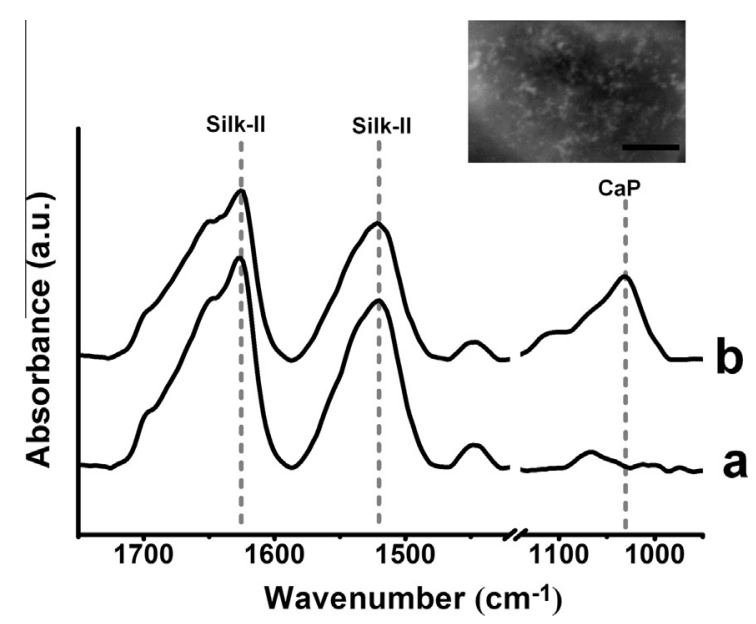

Fig. 1. ATR-FTIR spectra of (a) the silk layer and (b) the silk-nanoCaP layer in the bilayered scaffolds. The inserted image is a backscattered SEM image of the silknanoCaP layer, showing the nanosized CaP particle (white domain) distribution in the silk matrix (scale bar: $3 \mu \mathrm{m}$ ). 
conformation [41]. The silk-nanoCaP layer presented a strong peak at $1031 \mathrm{~cm}^{-1}$, which is the characteristic vibration absorbance of $\mathrm{PO}_{4}^{-3}$ in the CaP [42]. The size of the nano-CaP particles was analyzed by back-scattered SEM. The inserted SEM image shows that the CaP particles were distributed evenly in the silk matrix, and were $\sim 200 \mathrm{~nm}$ in size. TGA showed that the CaP mass ratio in the silk-nanoCaP layer was $\sim 13.81 \pm 0.63 \%(\mathrm{CaP} / \mathrm{Silk}, \mathrm{w} / \mathrm{w})$, and the $\mathrm{Ca} / \mathrm{P}$ ratio of the ash was $1.65 \pm 0.4 \%$.

\subsection{Microstructure and CaP distribution of the bilayered scaffolds}

Fig. 2 shows a macroscopic image of the bilayered scaffolds. It was found that the scaffold presented macro/microporous and interconnective structure in both layers. The two layers were well integrated by a continuous interface region. The pore size of the macropores in each layer was $\sim 300-700 \mu \mathrm{m}$, and the micropores were located in the trabeculae of the macropores with size $<50 \mu \mathrm{m}$ (Fig. 2b). The interface region was $<500 \mu \mathrm{m}$ thick and located flat between the two layers (Fig. 2b). EDX scanning from the silk-nanoCaP layer to the silk layer showed that calcium ions were only limited in the silk-nanoCaP layer and the thin interface area (Fig. 2c). In the interface region, the intensity of the calcium ion signal on the side close to the silk-nanoCaP layer was higher than the one in the side of the silk layer.

The qualitative and quantitative distributions of the porosity and the $\mathrm{CaP}$ in the bilayered scaffolds were assessed by microCT. Table 1 demonstrates that both layers presented high porosity and interconnectivity, and the CaP was retained only in the

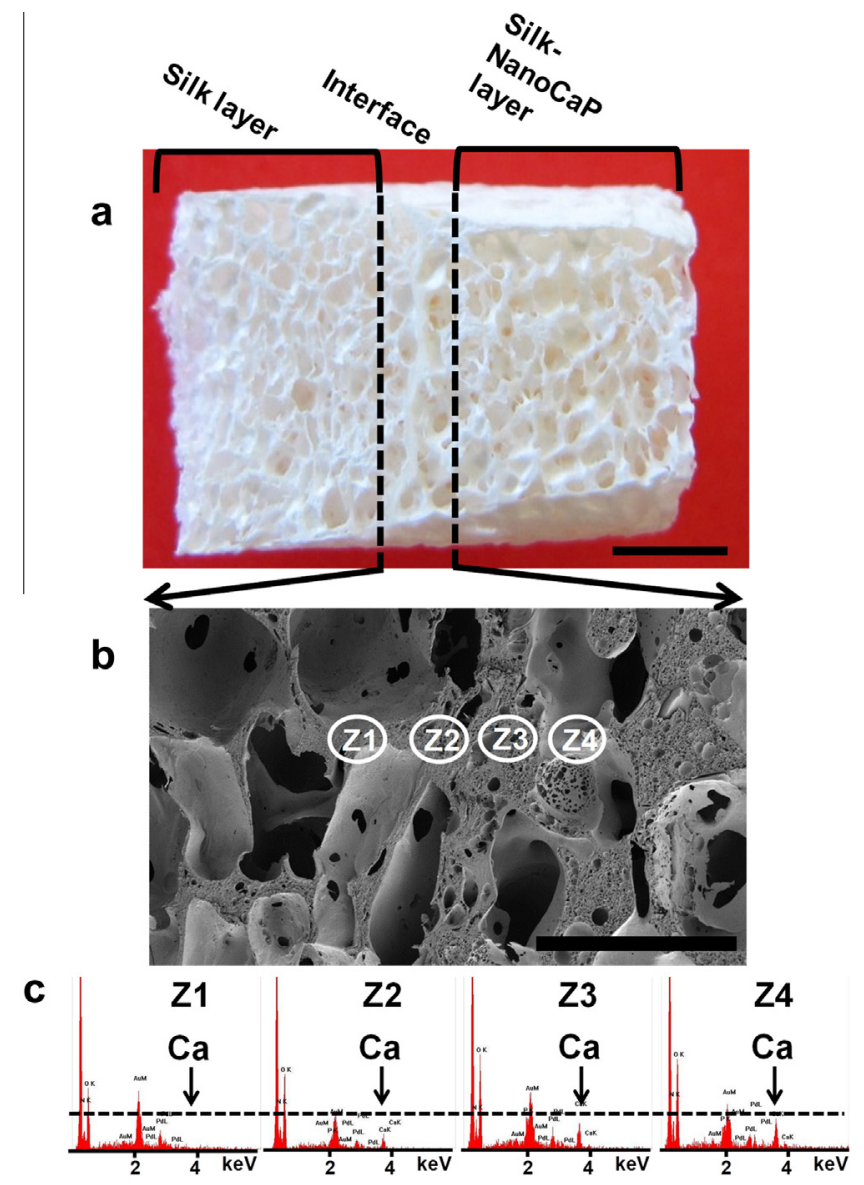

Fig. 2. The interface of the bilayered scaffolds. (a) Macroscopic image of the bilayered scaffolds (scale bar: $3 \mathrm{~mm}$ ). (b) SEM image of the interface region in the bilayered scaffold (scale bar: $500 \mu \mathrm{m}$ ). Z1, Z2, Z3 and Z4 indicate different regions from the silk layer to the silk-nanoCaP layer, around the interface area. (c) EDX elemental analysis of calcium ions in $\mathrm{Z} 1, \mathrm{Z2}, \mathrm{Z} 3$ and $\mathrm{Z} 4$ regions.
Table 1

Microstructure and CaP content of the bilayered scaffolds analyzed by micro-CT.

\begin{tabular}{lllc}
\hline & $\begin{array}{l}\text { Mean } \\
\text { porosity (\%) }\end{array}$ & $\begin{array}{l}\text { Mean } \\
\text { interconnectivity (\%) }\end{array}$ & $\begin{array}{l}\text { Mean CaP } \\
\text { content } \\
\text { (vol.\%) }\end{array}$ \\
\hline Silk layer & $82.02 \pm 1.15$ & $91.13 \pm 2.32$ & 0 \\
Silk-nanoCaP layer & $62.27 \pm 2.61$ & $70.03 \pm 4.62$ & $9.60 \pm 0.81$ \\
\hline
\end{tabular}

silk-nanoCaP layer. The 3-D images showed two distinct phases in the bilayered scaffold (Fig. 3a). The CaP (blue domain) resided only in the silk-nanoCaP layer, without infiltration into the silk layer. Both layers displayed high interconnectivity and porosities (Fig. 3a). By changing the threshold, it was found that the CaP distribution was homogeneous in the silk-nanoCaP layer (Fig. 3b). The 2-D images of each layer also confirmed the interconnectivity and porous structure in each layer (Fig. $3 \mathrm{c}$ and $\mathrm{d}$ ). The porosity distribution profile revealed that the porosity was homogeneously distributed in each layer, and lower porosity was observed in the silk-nanoCaP layer (Fig. 3e). The porosity showed a sharp decrease in the interface domain which was $\sim 0.5 \mathrm{~mm}$ in thickness. The CaP was distributed evenly in the silk-nanoCaP layer (Fig. 3f). It was noticed that the CaP content decreased gradually in the thin interface region and there was no CaP in the silk layer (Fig. 3f).

\subsection{Mechanical and degradation properties of the bilayered scaffolds}

As shown in Fig. 4a, the wet state modulus of the bilayered scaffolds was $\sim 0.4 \mathrm{MPa}$, similar to the ones of the controls. The dynamic viscoelastic properties of the scaffolds were evaluated by DMA. It was found that the storage modulus of the bilayered scaffolds increased from around 0.5 to $0.8 \mathrm{MPa}$ as the frequency increased from 0.1 to $20 \mathrm{~Hz}$ (Fig. 4c). In the frequency range tested, the storage modulus values of the bilayered scaffolds were similar to those of SC16 and higher than those of S16. All the three group scaffolds demonstrated similar and low loss factor values for the tested frequencies. The loss factor $(\tan \delta)$ of the bilayered scaffolds increased slightly from around 0.17 to 0.23 when the frequency increased from 0.1 to $20 \mathrm{~Hz}$. In this study, the enzymatic degradation profiles of the scaffolds were analyzed by using protease XIV. It was found that $\mathrm{S} 16$ degraded faster than the bilayered scaffolds and SC16 (Fig. 4b). In the first $12 \mathrm{~h}$, the bilayered scaffolds lost $\sim 12 \%$ mass, and S16 and SC16 lost $\sim 14 \%$ and $\sim 7 \%$ mass, respectively. After 7 days of degradation, the bilayered scaffolds presented $\sim 27 \%$ weight loss, and S16 and SC16 showed 43\% and $\sim 22 \%$ weight loss, respectively.

\subsection{Attachment, viability and proliferation of the RBMSCs on the bilayered scaffolds}

The RBMSCs were seeded into the bilayered scaffolds. The live/ dead assay showed that there were living cells attached on the surface of the scaffolds (Fig. 5a-c), after seeding for 3 days. The cells dispersed evenly in the silk and silk-nanoCaP layers, presented a spreading morphology, and contacted with each other. Some cells also grow on the interface area. Cell attachment was also observed by SEM after culturing for 7 days in basal condition (Fig. $5 d-f$ ). It was found that the surface of the silk layer, the silk-nanoCaP layer, and the interface were fully covered by the cells and the extracellular matrix, in both basal and osteogenic conditions. The cells not only adhered to the surface of the scaffolds, they also grew inside the scaffolds to a depth of at least $1 \mathrm{~mm}$ (Fig. $5 \mathrm{~g}, \mathrm{~h}$ ).

Quantitative analysis of the cell viability was performed by MTS assay (Fig. 6a). It was observed that the MTS absorbance significantly increased during the culture period. Cell proliferation was 

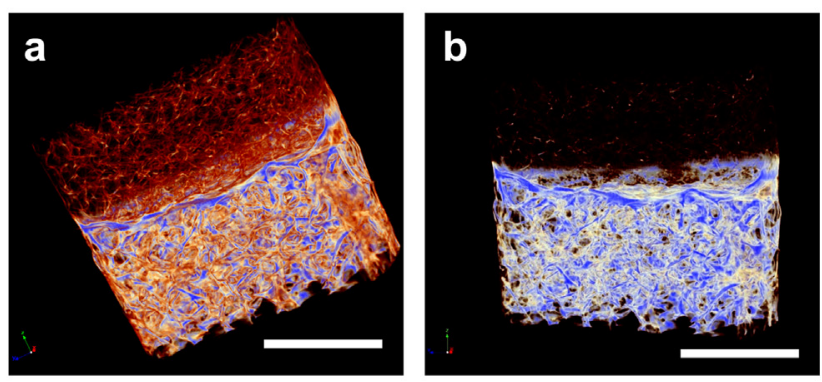

e

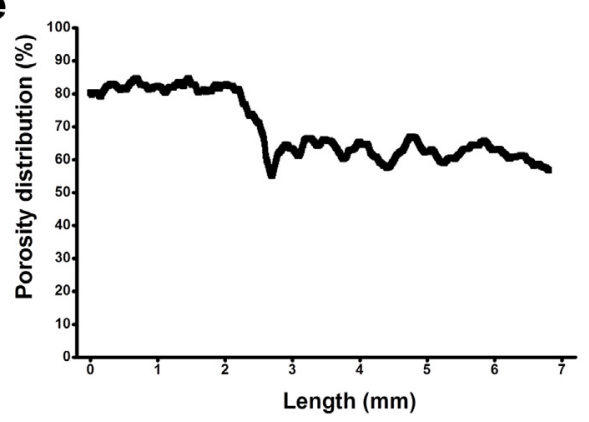

f

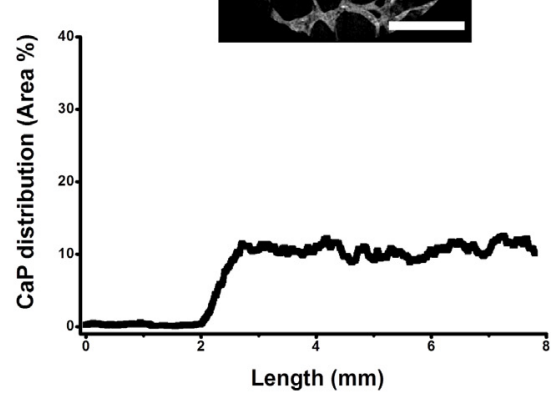

Fig. 3. Micro-CT analysis of the bilayered scaffolds. (a) 3-D image of the silk matrix (brown) and the CaP distribution (blue), and (b) 3-D image of the pure CaP distribution in the bilayered scaffold (scale bar: $4 \mathrm{~mm}$ ). (c) 2-D image of the silk layer, and (d) 2-D image of the silk-nanoCaP layer (scale bar: $1 \mathrm{~mm}$ ). (e) Quantitative analysis of the porosity distribution, and (f) quantitative analysis of the CaP distribution in the bilayered scaffolds.

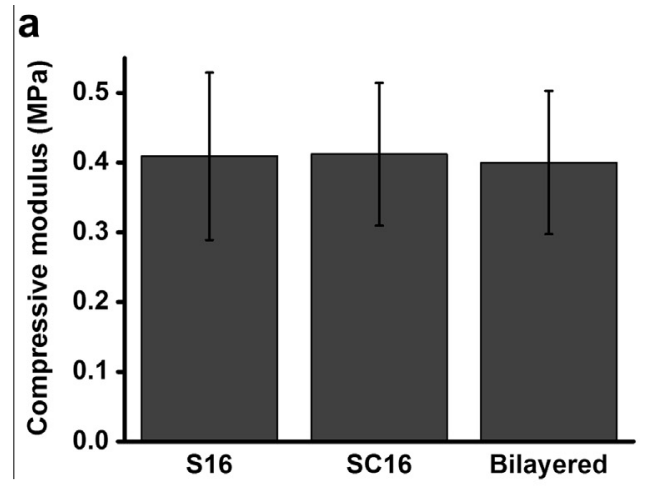

b
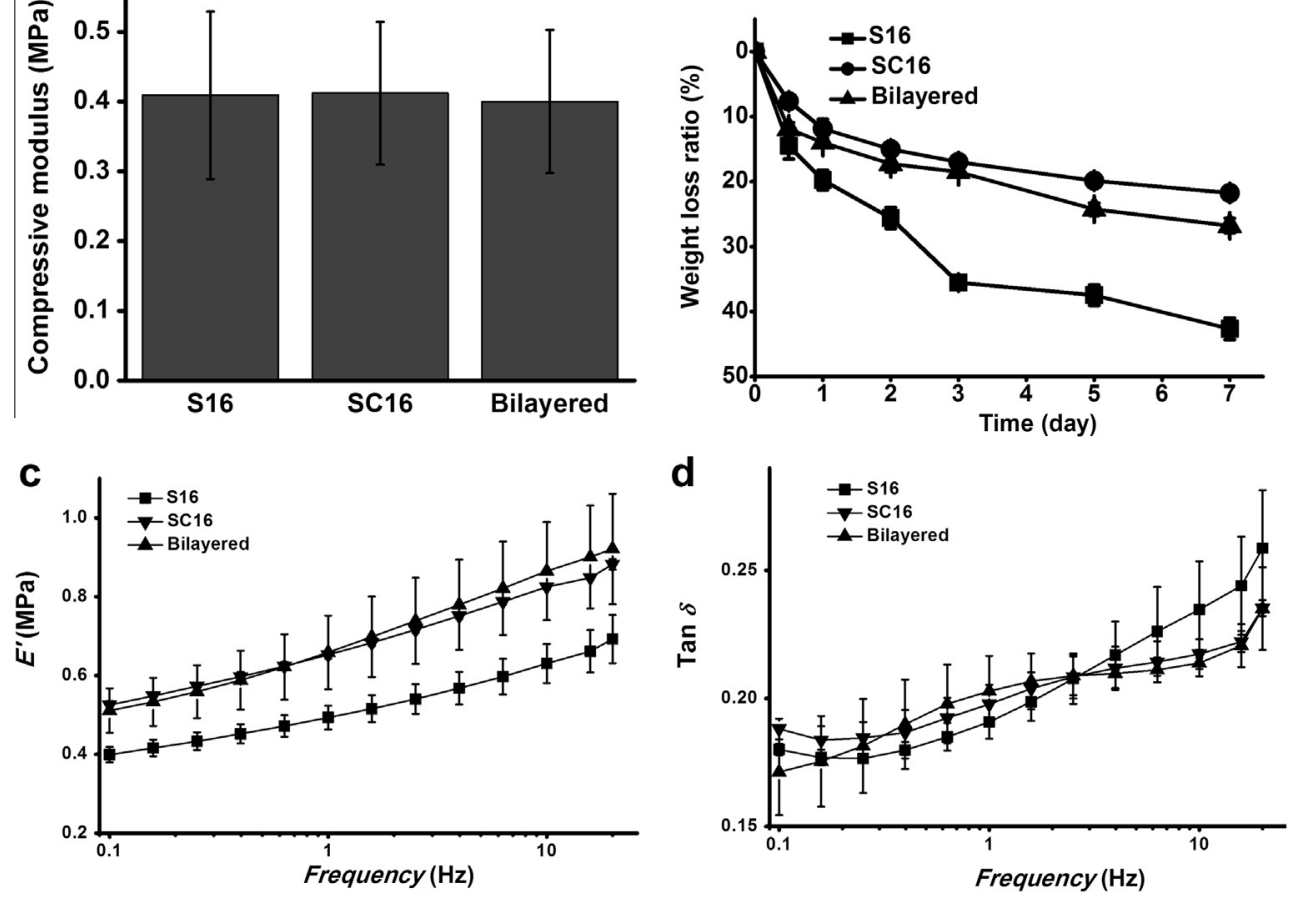

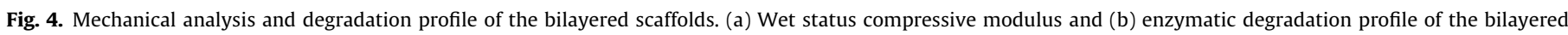
scaffolds and the controls. (c) Storage modulus ( $\left.E^{\prime}\right)$ and (d) loss moduli (tan $\delta$ ) of the bilayered scaffolds and the controls obtained by DMA, tested at $37{ }^{\circ} \mathrm{C}$ in PBS.

screened by DNA content analysis. It was seen that the DNA content of the bilayered scaffolds significantly increased from day 7 to day 14 , in both the basal and osteogenic conditions (Fig. 6b). At day 14, the DNA content of the bilayered scaffold in the basal condition was higher than that in osteogenic media (Fig. 6b).

\subsection{Osteogenic differentiation of RBMSCs in the bilayered scaffolds}

The ALP activity from the cells seeded in the bilayered scaffolds and the controls were normalized by their respective DNA content (Fig. 6c). It was found the ALP activity in all the groups increased 


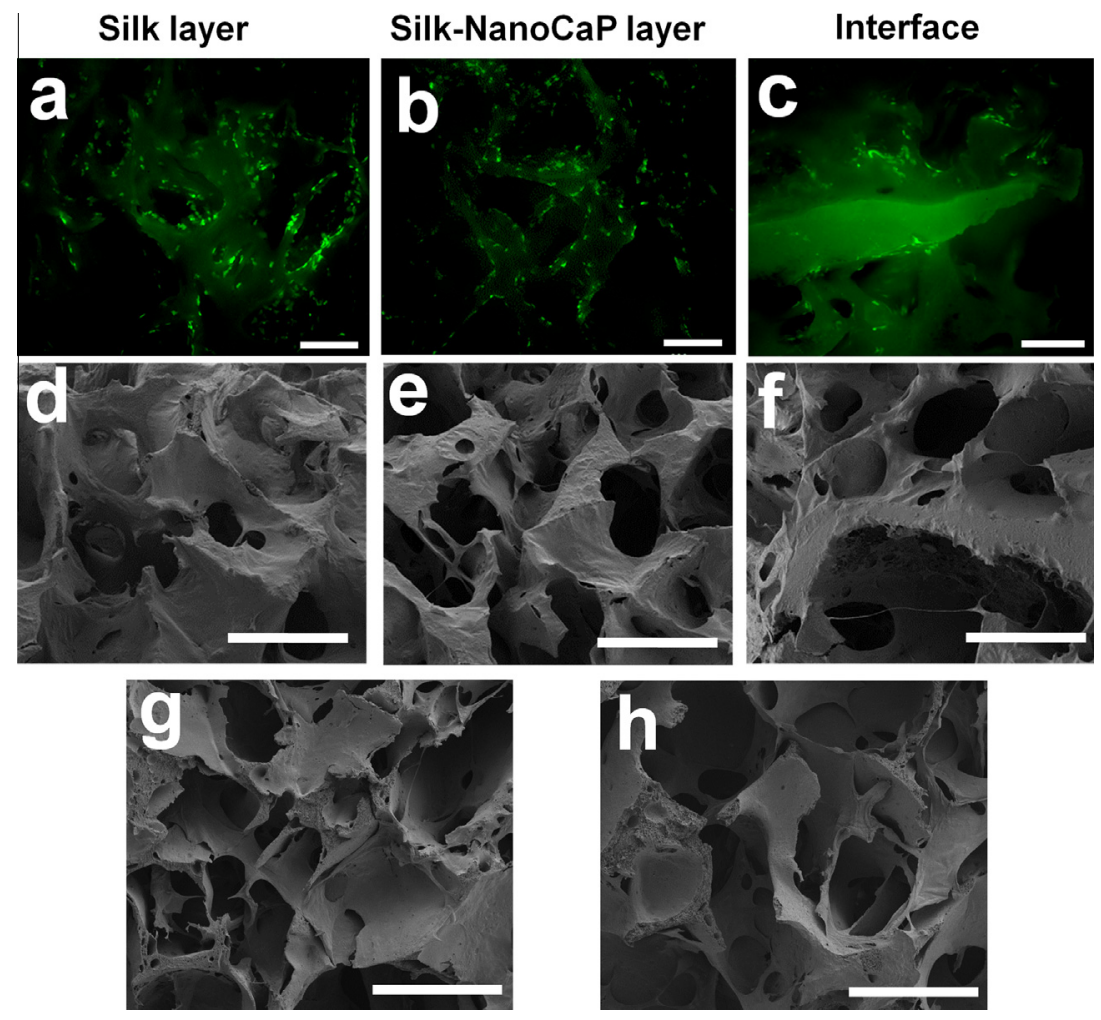

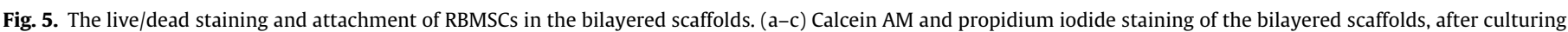

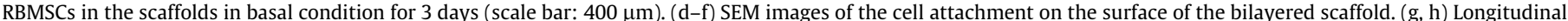

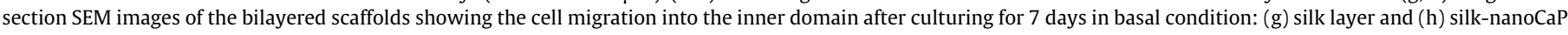
layer (scale bar: $500 \mu \mathrm{m}$ ).

from day 7 to day 14, in osteogenic conditions. In basal condition, the ALP activity showed no differences during the culture time. In osteogenic conditions, the ALP activity of the silk-nanoCaP layer was significantly higher than that of the silk layer at both tested time points. The same trend was observed in the controls. The ALP activity of SC16 was higher than that of S16 in day 7 and day 14 , when cultured in osteogenic conditions.

\subsection{Subcutaneous implantation of the bilayered scaffolds}

The in vivo compatibility of the bilayered scaffolds was assessed by subcutaneous implantation in rabbit. Fig. 7a showed that the bilayered scaffolds were still integrated after 4 weeks of implantation. A layer of connective tissue adhered on the entire surface of the scaffolds, and no signs of infection or acute inflammation were observed. The SEM images of the explants showed that the connective tissues not only tightly integrated to the implants, but also fully filled the inner pores of the bilayered scaffolds (Fig. 7b). The H\&E staining image of the bilayered scaffolds showed that the connective tissues infiltrated into the pores of the scaffolds (Fig. 7c-e). There were some vessels formed inside the scaffolds (Fig. 7c). Only a few macrophages were observed in the inner part of the scaffolds. There were also some fibroblasts presented in the silk-nanoCaP layer.

\subsection{Regeneration of rabbit knee OCDs by the bilayered scaffolds}

The OC regeneration potential of the bilayered scaffolds was studied by implantation of these scaffolds in rabbit OCDs for 4 weeks. The macroscopic images of the explants demonstrated that the scaffolds were integrated well with the host tissue (Fig. 8a). The scaffolds implanted displayed no obvious mass loss.
There were no apparent signals of infection of the implants. The defect controls were not regenerated and formed a large void with apparent adjacent tissue collapse. The micro-CT analysis of the explants illustrated that the defect filled with the bilayered scaffold presented less void space and more regular morphology compared with the defect control (Fig. 8b). Moreover, both the ingrowths of the subchondral bone in the bottom domain and the regeneration of cartilage in the surface area of the implant were observed. From the micro-CT data, it is not easy to clearly determine the amount of CaP coming from the scaffold and the new bone. However, based on the scanning parameter (high voltage) chosen for this assay, the detected CaP may mainly come from the newly formed subchondral bone. The defect control showed no cartilage regeneration and little subchondral bone formation. The porosity distribution showed that the defect control was empty in the top region and filled by the tissues in the bottom region, while the defects with implants showed $<20 \%$ porosity in the region analyzed (Fig. 8c). The defect control showed only a very small amount of subchondral bone regeneration in the bottom, but the defect with the implant presented a large amount of CaP content in the silk-nanoCaP layer (Fig. 8d). The quantitative results of CaP content and porosity of different regions were presented in Supplementary Table 1 . The defect controls showed much higher void space than the defects with implants. It was observed that the CaP content in the silk-nanoCaP layer was $20 \%$ higher than the one from the silk layer.

The explants were further evaluated by H\&E and Masson's trichrome staining (Fig. 9). No acute inflammation was observed in any of the explants. The defects with scaffolds showed no collapse of adjacent tissues. The scaffolds presented a stable and integrated structure, and were firmly integrated with the host tissues. In the silk layer, the new cartilage formed and gradually spread from 

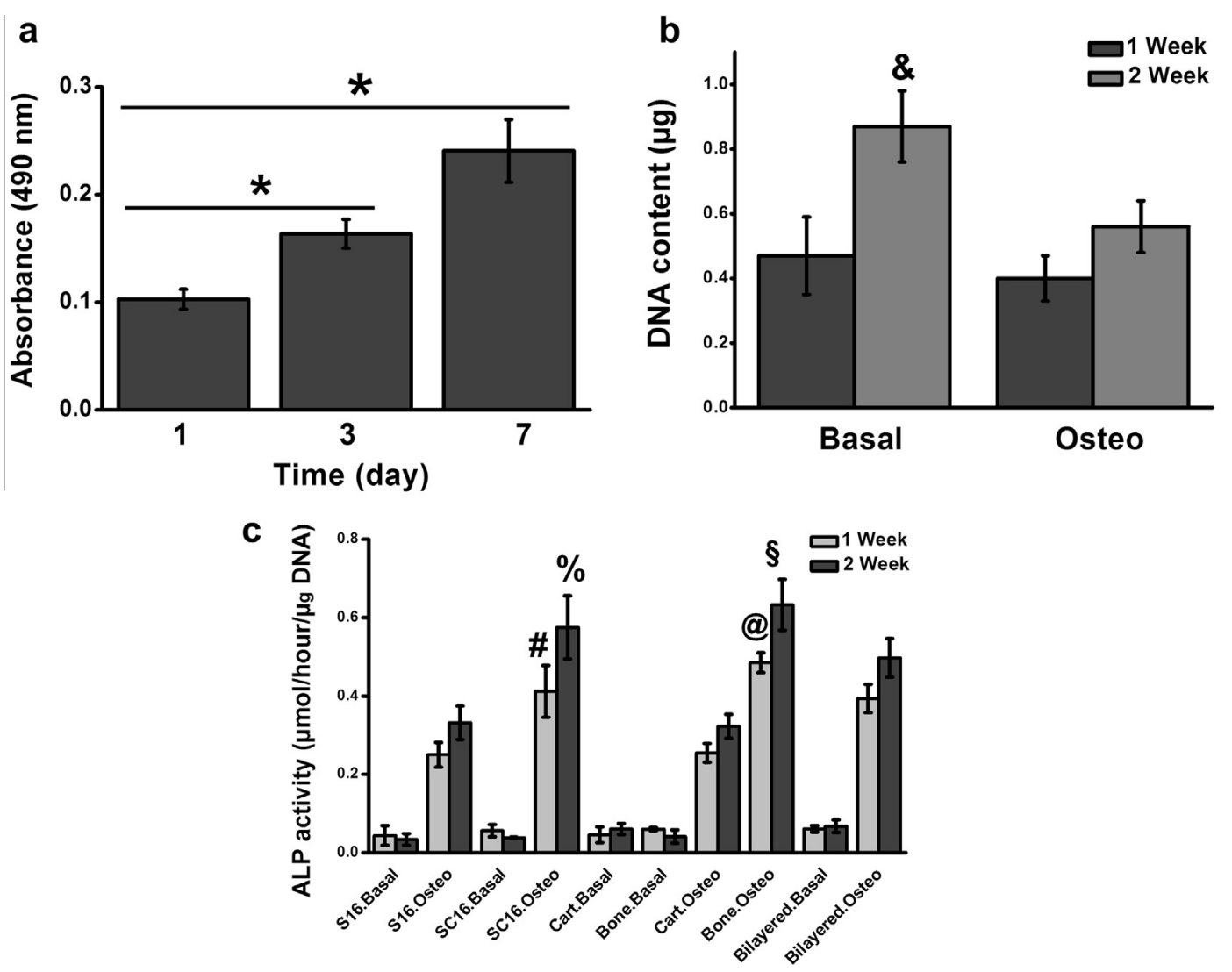

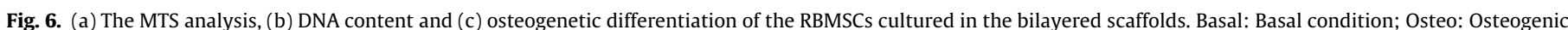

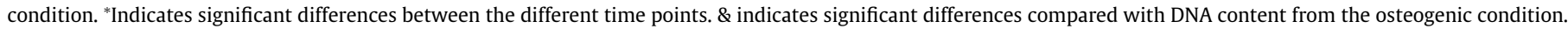

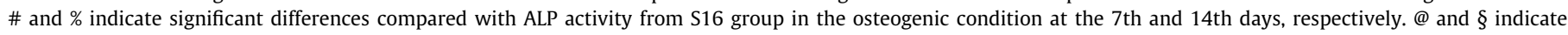
significant differences compared with values from the silk layer in the osteogenic condition at the 7 th and 14 th days, respectively.

the edge to the middle of the defects (Fig. 9a,b). The top surface of the scaffolds showed no collapse, and matched the height of the normal cartilage. In the bottom domain, obvious new subchondral bone growth into the silk-nanoCaP layer was observed (Fig. 9a,b). The infiltration of the subchondral bone was limited to the silknanoCaP layer. From the cross-sectional staining, a low level of deformation was observed. In addition, de novo bone infiltration was observed in the subchondral part, which shows a good integration of the scaffolds in the host tissue (Fig. 9c,d). The defect control showed no regeneration of the cartilage layer and the subchondral bone (Fig. 9e,f). From the high-magnification Masson's trichrome staining images (Fig. 10a), it could be seen that the chondrocytes in the neocartilage presented a normal round phenotype and grew inside the silk layer. The defect control only showed loose tissue formation (Fig. 10c). In the silk-nanoCaP layer, besides the obvious new bone ingrowth, the formation of new vessels was also detected (Fig. 10b). Some collagen fiber formed under the loose tissue in the subchondral bone domain of the defect control (Fig. 10d).

The formation of glycosaminoglycan (GAG) in the defect was studied by Safranin $O$ staining. It was found that the explants exhibit GAG tissue-containing chondrocytes that formed in the edge and extended into the interior region of the top silk layer (Fig. 11a,b). However, the defect control did not present any positive staining of cartilage matrix (Fig. 11c,d). With the collagen II immunohistochemical staining, it was found that the neocartilage tissue formed inside the silk layer was positively stained for collagen II (Fig. 12a). The defect control did not show positive staining of collagen II (Fig. 12c). Considering the important role of angiogenesis in bone regeneration, an immunohistochemical staining of an angiogenic marker (i.e. SNA-lectin) was performed (Fig. 13). The specificity of SNA-lectin for endothelial cells enabled observation of a substantial invasion of the silk-nanoCaP layer by the endothelial cells (Fig. 13a). In the defect control (Fig. 13c), it was possible to observe the endothelial cells mainly located in the surface area of the defect. The enlarged SNA-lectin staining image showed that abundant endothelial cells colonized the interior region of the silk-nanoCaP layer, and the formation of new bone and blood vessel was also identified (Fig. 13e). The defect control did not present new bone formation and displayed much lower endothelial cell density compared with the defect with implant (Fig. 13g). The newly formed vessels in the defect control were not as evident as those in the defect with implants (Fig. 13e,g).

\section{Discussion}

OC tissue encompasses interconnected chondral and subchondral bone layers, which present distinct properties. Only chondrocytes reside in the avascular chondral layer, with type II collagen and proteoglycan being the main components in the extracellular matrix. On the other hand, many kinds of cells (e.g. osteoblasts, osteoclasts and bone marrow cells) exist in the vascularized subchondral bone layer which primarily consists of hydroxyapatite and type I collagen. Therefore, in OC tissue engineering, it is feasible to generate bilayered scaffolds that possess different features (e.g. mechanical, chemical or morphology properties) in each layer to satisfy the simultaneous regeneration of the chondral layer and the subchondral bone layer. The ideal scaffolds for OCD regeneration should be those that can promote cartilage regeneration on 

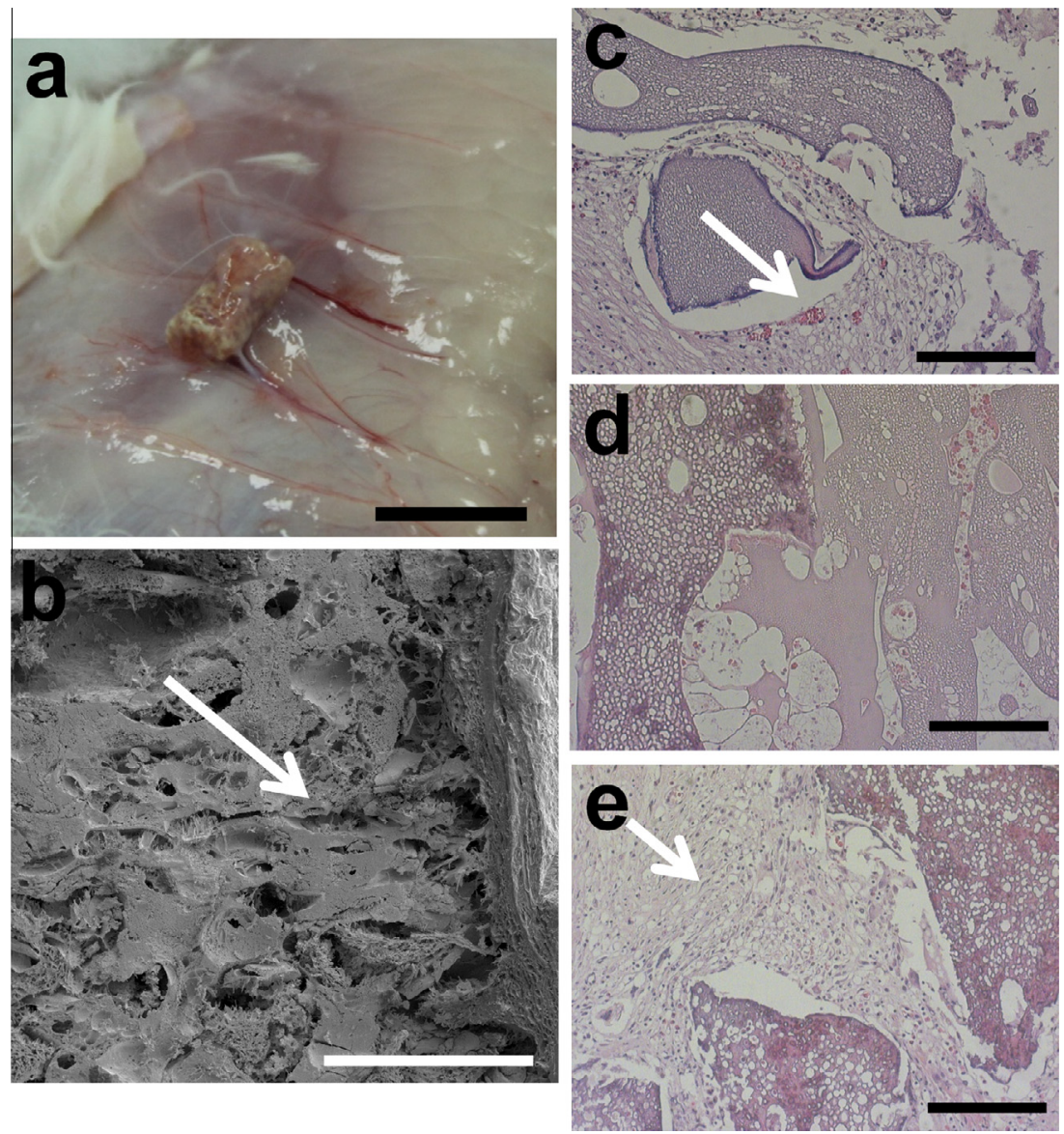

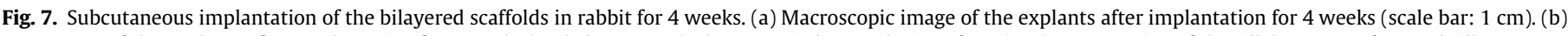

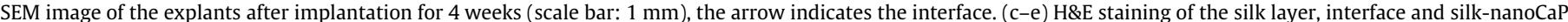
layer in the explants after implantation for 4 weeks, respectively (scale bar: $200 \mu \mathrm{m}$ ). The arrow in (c) indicates vessels, and the arrow in (e) indicates fibroblasts.
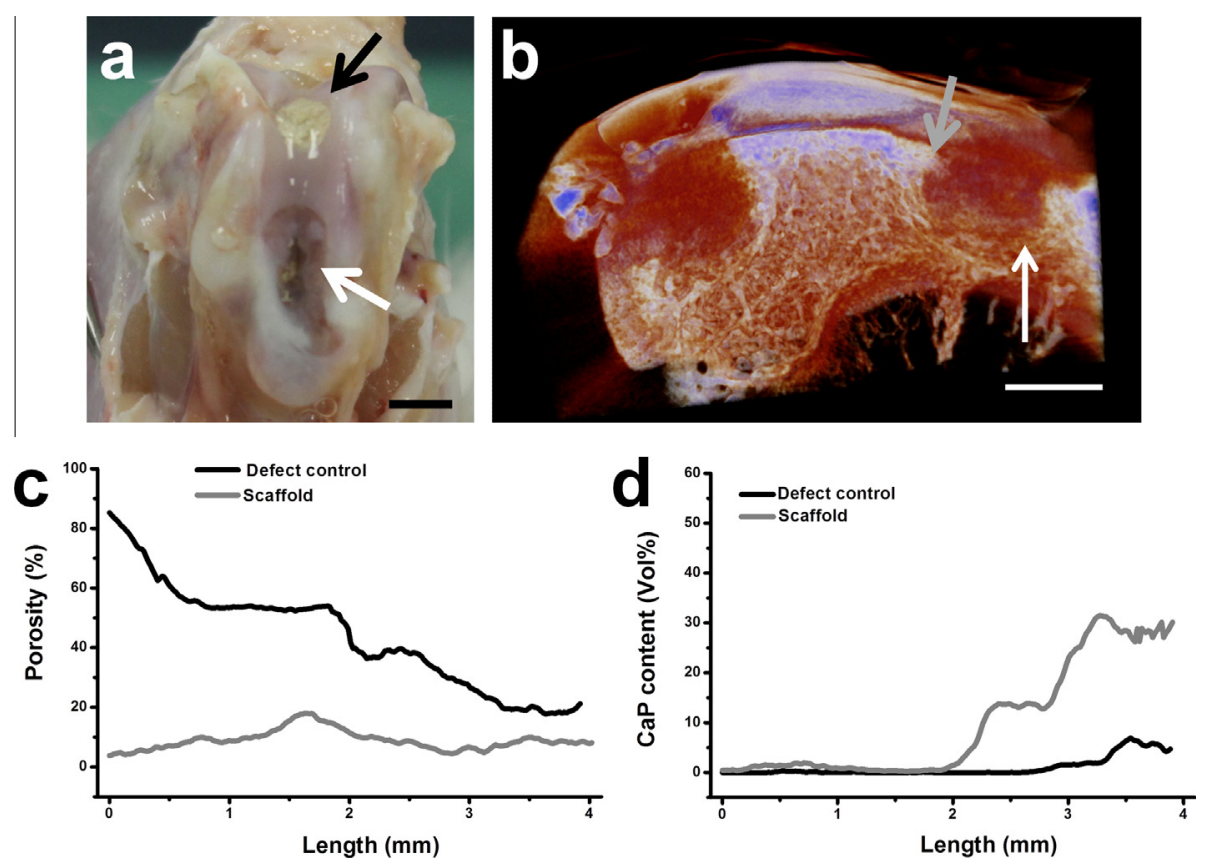

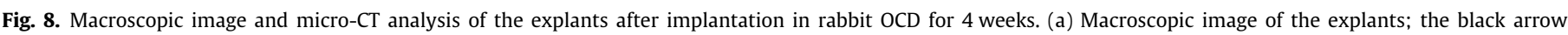

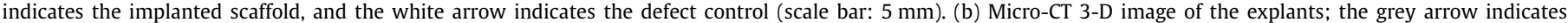

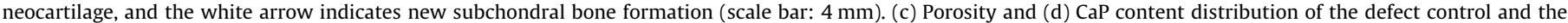
defect implanted with the bilayered scaffold. 

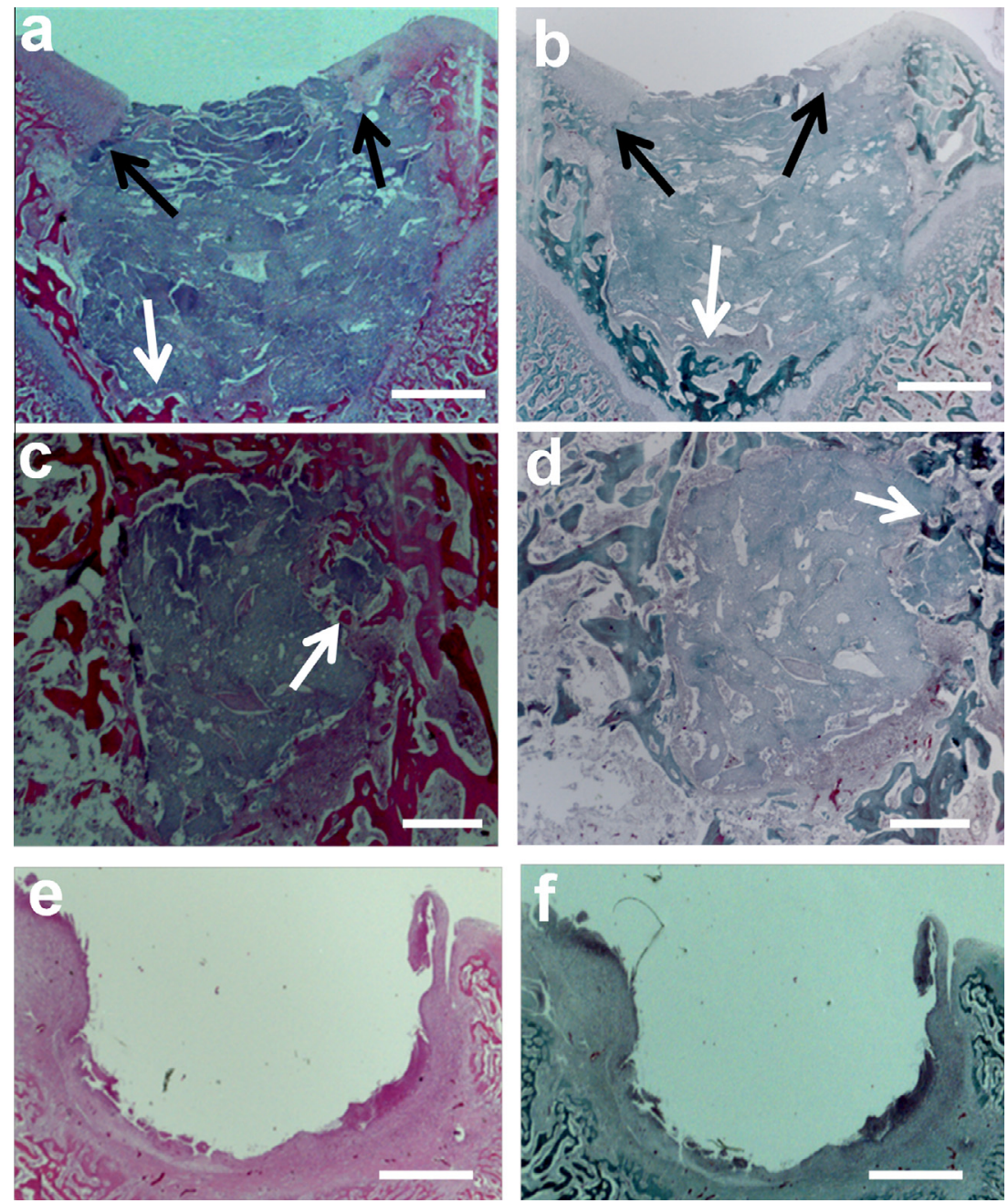

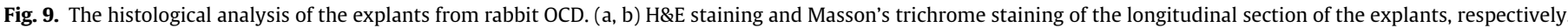

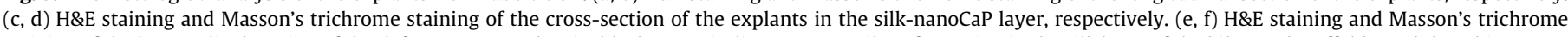

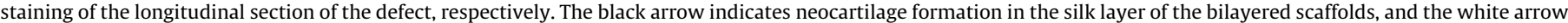
indicates new subchondral bone formation inside the silk-nanoCaP layer of the bilayered scaffolds. Scale bar: $1 \mathrm{~mm}$.

one side and encourage fast subchondral bone repair on the other. In this study, we proposed bilayered silk/silk-nanoCaP scaffolds for OCD regeneration and evaluated their potential by in vitro and in vivo studies. These bilayered scaffolds are based on our previous works on high-strength SF scaffolds and nanocomposite silk/nanocalcium phosphate scaffolds [37,38,43].

Compared to previous studies [37,38], the bilayered scaffolds maintained the chemical properties (Fig. 1 and TGA) and the microstructure (Figs. 2 and 3) of S16 and SC16 in the chondral and subchondral layer, respectively. Tissue regeneration requires that scaffolds present a porous and interconnected structure, as well as a suitable pore size and distribution [44]. It has been reported that a pore size larger than $300 \mu \mathrm{m}$ is favorable for cell proliferation, nutrients exchange and new tissue formation in bone regeneration; and the micropores related to the surface roughness are good for cell attachment. Thus, the macro/microporous structure in the subchondral layer may promote better cell attachment, bone tissue filtration and angiogenesis compared with the sole macroporous or microporous structure.

Based on their adequate performance for bone regeneration [35], it is believed that CaP-based materials also favor subchondral bone regeneration. However, it was also reported that $\mathrm{CaP}$ can induce the hypertrophy of chondrocytes [45]. It is important to precisely control the distribution of the CaP in the bilayered scaffolds, avoiding the $\mathrm{CaP}$ migration to the layer free of $\mathrm{CaP}$ (addressed to cartilage). EDX (Fig. 2b,c) and micro-CT (Fig. 3a,b,f) analyses demonstrated that the introduced CaP was clearly confined to the silk-nanoCaP layer.

The mechanical property of the scaffolds is one of the main issues when addressing bone and cartilage tissue regeneration [51]. Improving the mechanical properties of the scaffolds is a major challenge for skeletal-related tissue engineering. Some studies have been performed to produce silk-based scaffolds of high strength for bone tissue engineering [52,53]. The typical Young's modulus of articular cartilage was reported to be $\sim 1 \mathrm{MPa}$ [54]. Despite the different testing approach, the strength of the bilayered scaffolds is comparable to that of human articular cartilage (Fig. 4a). Table 2 listed the mechanical properties of previously reported natural polymer scaffolds. It was reported previously the bilayered scaffolds have a dry compressive modulus of $\sim 16 \mathrm{MPa}$ [40]. In comparison with other previous studies on silkbased scaffolds, the bilayered scaffolds described herein present superior compressive modulus $[30,47,48,50,46]$. Furthermore, the modulus of the bilayered scaffolds was much higher than those 

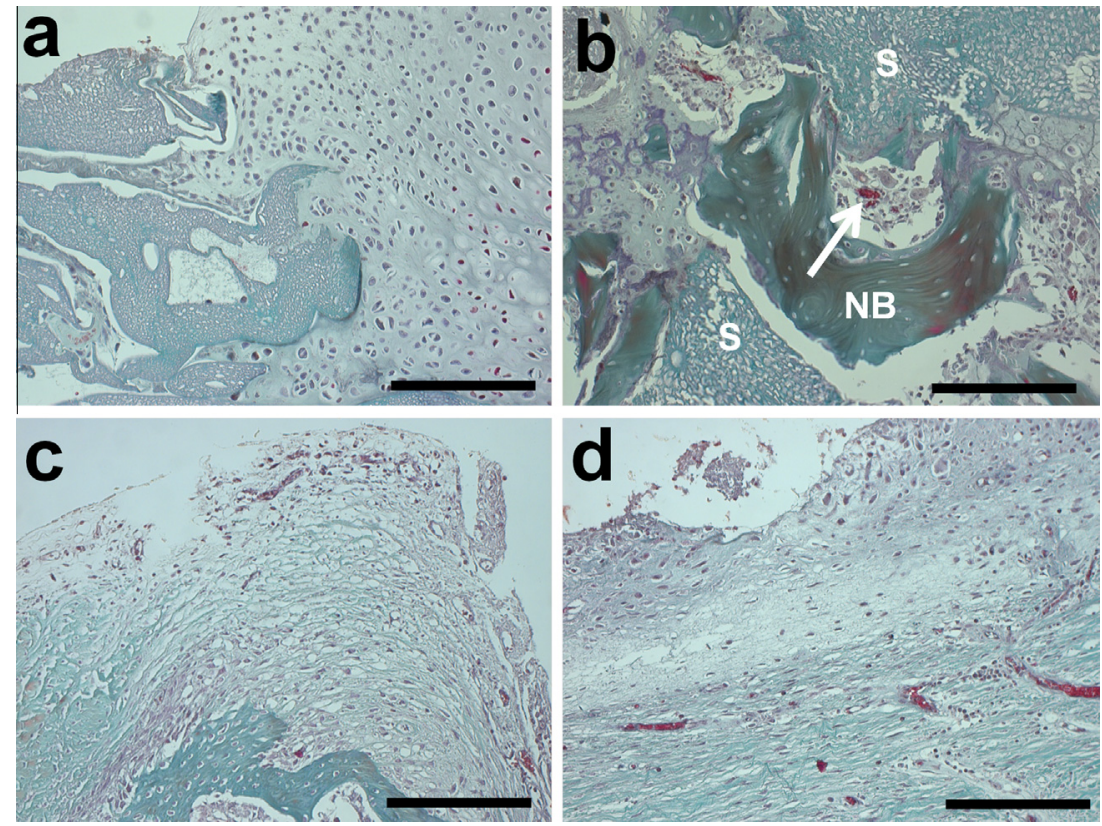

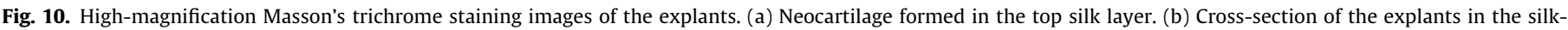

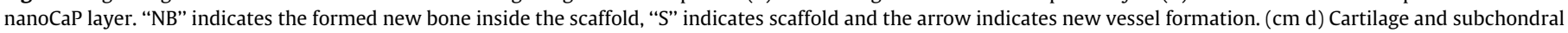
bone domains in the defect control, respectively. Scale bar: $200 \mu \mathrm{m}$.
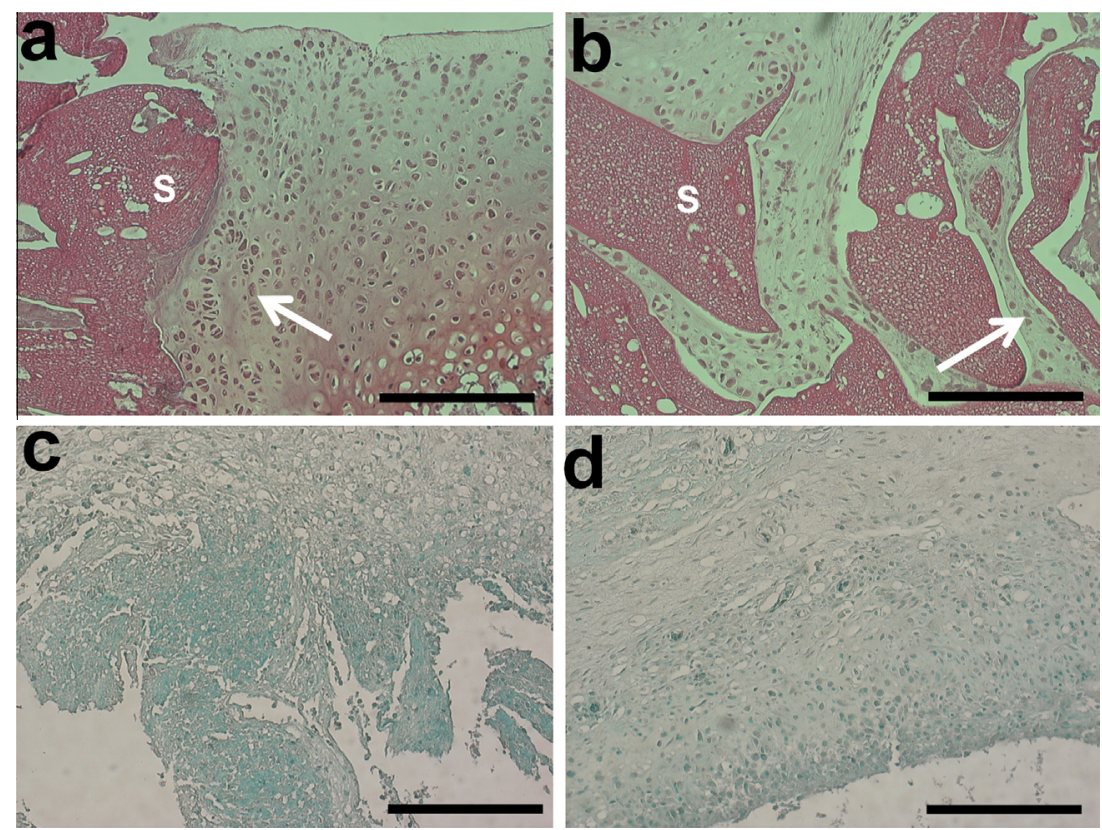

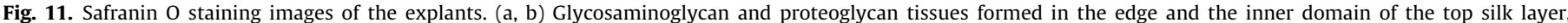

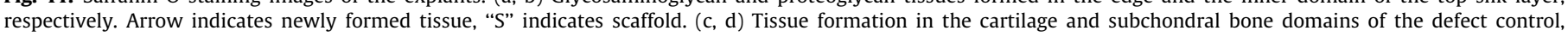
respectively. Scale bar: $200 \mu \mathrm{m}$.

of polysaccharide- and protein-based scaffolds (Table 2). Scaffolds implanted in the body undergo dynamic loading, and thus it is crucial to know their dynamic mechanical properties under physiological conditions. It was demonstrated that the binding strength of the two layers was excellent, as the bilayered scaffolds maintained their integrity under high-frequency loading. The low loss factor showed that these scaffolds were of low viscosity and high elasticity.

In an ideal tissue engineering approach the scaffolds should degrade in the body after implantation. In previous studies, it was shown that salt-leaching scaffolds gradually lost weight when immersed in isotonic solution for 1 year [39]. SC16 displayed a slightly higher weight loss profile as compared with S16, due to the dissolution of CaP. When implanted, the scaffolds would contact with the body fluid, which is rich in enzymes. The study of the enzymatic degradation of scaffolds is of great importance to predict their in vivo stability. The bilayered scaffold, containing both silk layer and silk-nanoCaP layer, presented a degradation ratio in between those observed for S16 and SC16. The differences in the degradation profiles could be attributed to the formation of 

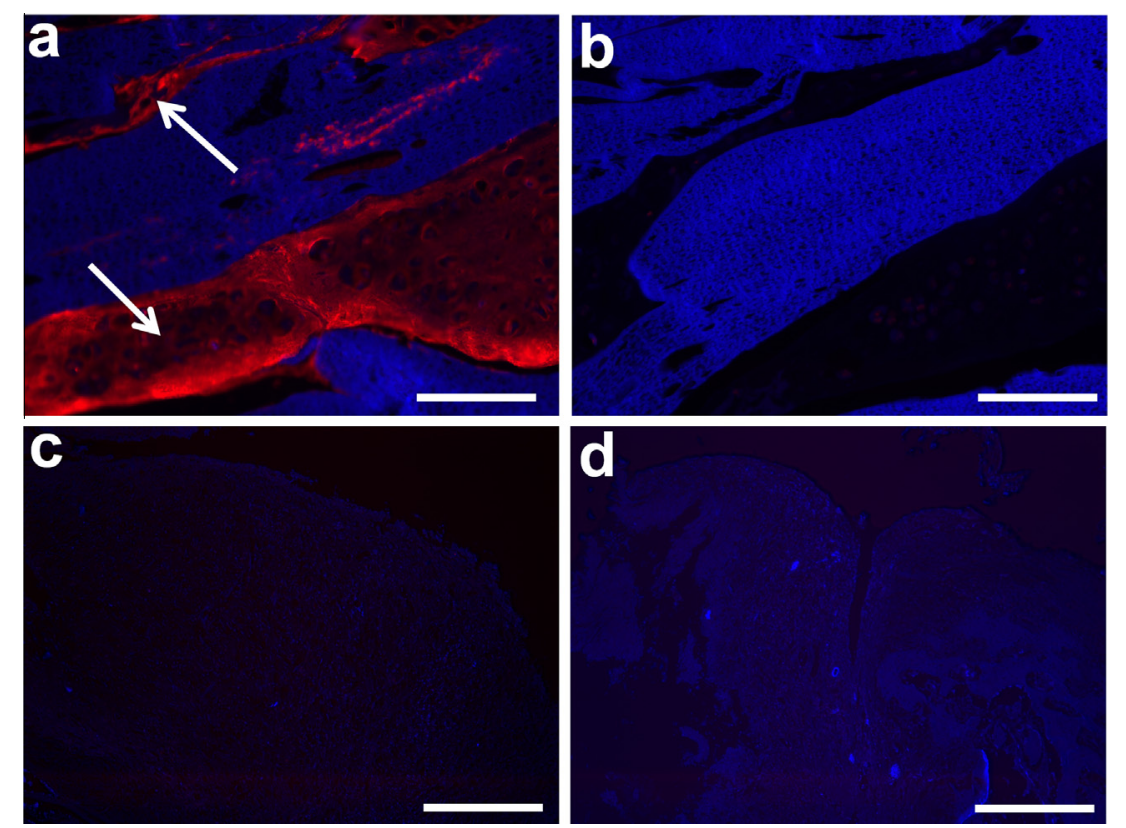

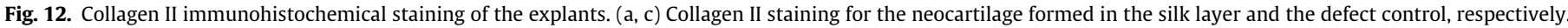
(b, d) Negative control for (a, c), respectively. (a, b) Arrows indicate collagen II (red) in the regenerated cartilage, blue domain indicates the scaffold. Scale bar: 100 m.

silk-CaP complex in the silk-nanoCaP layer. The silk and CaP formed a nanosize complex which hindered the enzymatic degradation process.

In order to achieve good tissue regeneration outcomes, it is necessary to evaluate the cytotoxicity of the scaffolds by seeding cells onto the scaffolds and observing cell viability, attachment, proliferation and differentiation. Bone marrow stromal cells are multipotent somatic stem cells and can be differentiated into osteoblasts, chondrocytes and adipocytes [16]. They have been studied as cell sources for OCD regeneration [16]. The outstanding performance of the bilayered scaffolds for cell seeding was related to the intrinsic properties of SF and CaP, as well as to the porous structure of the scaffolds. SF fiber has long been used as a suture for wounds [55] due to its compatibility with human tissues. SF-based biomaterials can be proteolytically degraded and subsequently metabolized in vivo [55]. SF has been prepared into membranes and scaffolds for cell culture or implantation, and the outcomes were satisfactory [29]. CaP-based materials, presenting similar chemical properties to the inorganic phase in bone, have thus been developed into implantation materials for bone regeneration [56]. The salt-leaching/freeze-drying approach endowed the bilayered scaffolds with proper hydration property [40], suitable pore size, high porosity and interconnectivity, all of which are important for supporting cell ingrowth, migration, proliferation and nutrient transportation.

Interestingly, the silk-nanoCaP layer induced a higher ALP activity as compared with the silk layer when the bilayered scaffolds were cultured in osteogenic medium (Fig. 6c). ALP is an important marker of osteogenesis differentiation. This indicates that the incorporated CaP facilitated the RBMSCs toward osteogenic differentiation. The observation from S16 and SC16 also confirmed this conclusion. This result also confirmed that the silk layer was not affect by the silk-nanoCaP layer during the osteogenic differentiation of RBMSCs, and the silk-nanoCaP layer was suitable for subchondral bone regeneration. This data can be related to the previous observation that only the silk-nanoCaP layer supports apatite crystal formation when the bilayered scaffolds are immersed in simulated body fluid [40]. Our observation is also in line with the previous study on CaP/silk hybrid scaffolds [57]. In that study, the CaP/silk scaffolds induced higher ALP activity compared with the silk scaffold.

The compatibility between the bilayered scaffolds and in vivo tissues was first analyzed by subcutaneous implantation. Due to the crystalline structure of the SF, the bilayered scaffolds maintained their integrity and kept their shapes. This result also revealed that the scaffolds retained good mechanical strength in vivo, which is in good agreement with the in vitro wet compressive modulus analysis. These scaffolds can support tissue ingrowth and angiogenesis, present good biocompatibility in vivo, and only induce minimum foreign body reaction (Fig. 7). The high porosity and interconnected structure (Figs. 2 and 3 ) contribute to the tissue ingrowth and angiogenesis of the bilayered scaffolds. Similarly, a previous study on SF-fiber-reinforced SF scaffolds showed inflammatory cells surrounded all the scaffolds at the first week and fewer inflammatory cells at the fourth week, in a subcutaneous mice model [52].

To evaluate the potential of the bilayered scaffolds for OCD regeneration, rabbit $O C D$ was used as a model in this study. Previously, it was reported that collagen/nanohydroxyapatite scaffolds (MaioRegen ${ }^{\circledR}$ ) would swell in contacted with blood, causing problems with fixation [21]. In this study, the fixing of the scaffolds was easy and the scaffolds maintained their dimensions without obvious swelling when in contact with body fluid during the implantation, which is of clinical relevance. It is obvious that significant swelling of the scaffolds could cause problems during implantation, such as scaffold protrusion into the meniscus domain. Besides the good stability observed for the bilayered scaffolds, these scaffolds also promoted subchondral bone regeneration (Fig. 8d and Supplementary Table 1). Based on the scanning condition used for the explants during the micro-CT analysis, the $\mathrm{CaP}$ content detected in the silk-nanoCaP layer mainly came from the newly formed subchondral bone. In a clinical trial, it was reported that the failure in the reconstruction of patellar came from the slow regeneration of subchondral bone [22]. The promising results in this study showed that the implantation of the bilayered scaffolds in a rabbit knee osteochondral critical size defect can induce rapid subchondral bone integration and healing. The fast formation of new subchondral bone is critical to fix the implant 

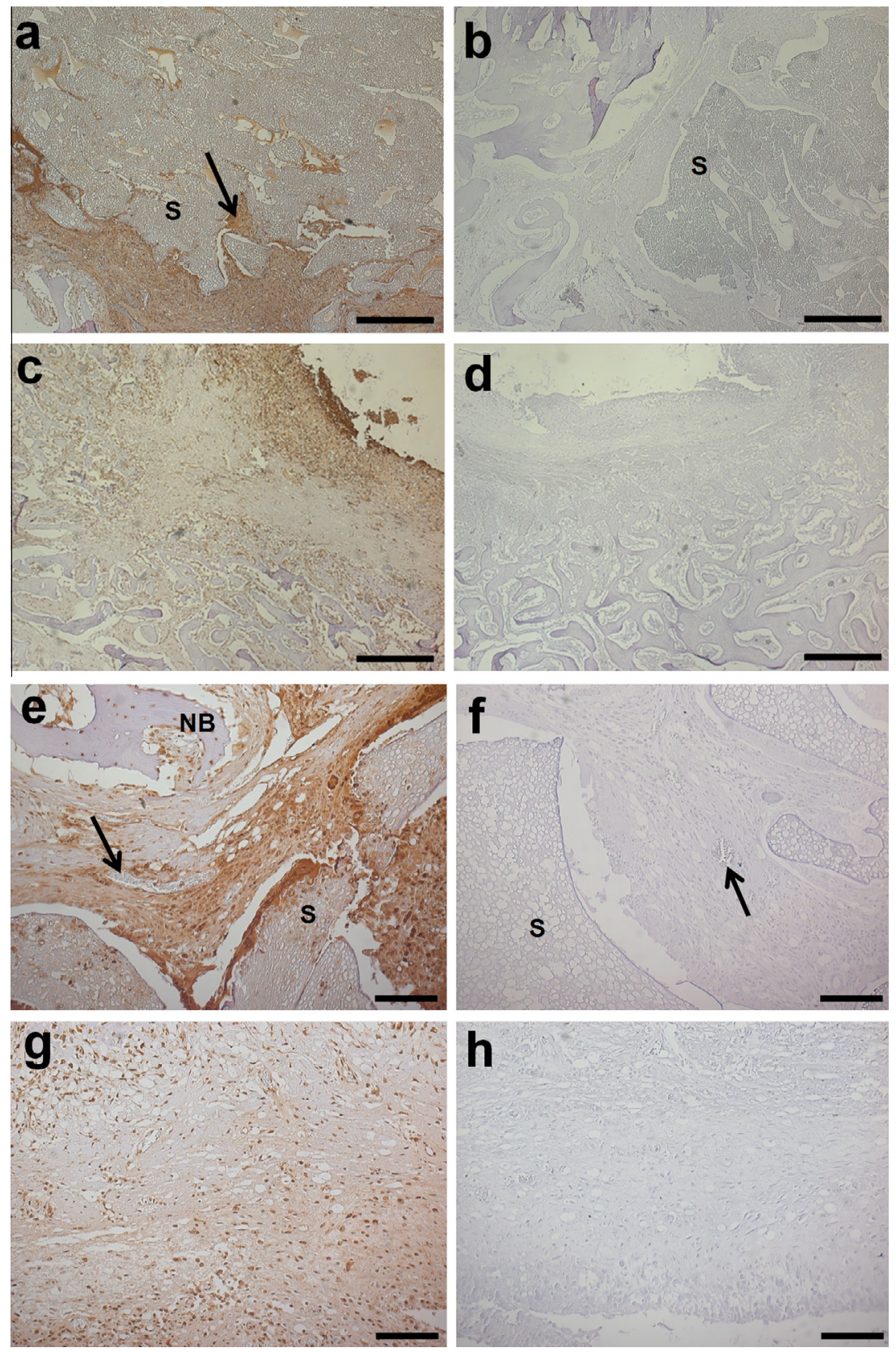

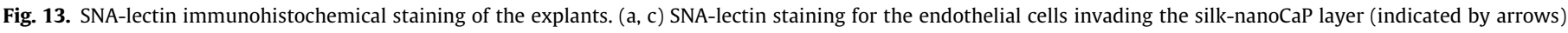

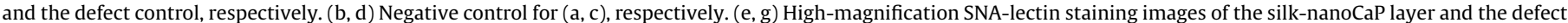

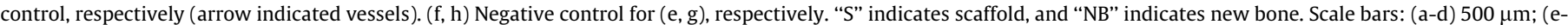
h) $100 \mu \mathrm{m}$.

in the defect site, as well as to provide mechanical support for the regeneration of cartilage layer. In the empty defect, only a small amount of subchondral bone was formed (Fig. 8d).

The regeneration of OC tissue was further evaluated by histological studies and immunohistochemistry. One of the challenges for OCD regeneration is the formation of normal hyaline cartilage, the main components of which are collagen II and GAG [10]. The current study showed that the top silk layer was advantageous in supporting cartilage regeneration, as indicated by significant collagen II formation (Fig. 12a) and GAG production (Fig. 11a,b), as well as assisting the infiltration of chondrocytes with normal morphology (Figs. 10 and 11). Another issue adversely affecting OCD healing is rapid subchondral bone formation and vascularization within the bone [34]. It has been reported that angiogenesis is an important process during the formation of pre-vascular networks, and endothelial cells play a unique role in angiogenesis [34]. Encouragingly, angiogenesis was clearly observed in the silk-nanoCaP layer (Fig. 13a,e). Furthermore, the silk-nanoCaP layer could induce new bone ingrowth and vessel formation (Figs. 10b and 13e); the latter would be helpful for new bone formation. These results have shown that the silk/silk-nanoCaP bilayered scaffolds support the rabbit knee OCD regeneration. 
Table 2

Compressive modulus of 3-D porous natural polymer scaffolds.

\begin{tabular}{|c|c|c|c|}
\hline Scaffold materials & Compressive modulus ( $\mathrm{kPa}$ ), dry state & Compressive modulus ( $\mathrm{kPa}$ ), wet state & Porosity (\%) \\
\hline Silk $^{\mathrm{a}}$ & $1,300 \pm 40$ & 75 & $92 \pm 1.3$ \\
\hline Silk $^{\mathrm{b}}$ & $1,000 \pm 75$ & $<10$ & $98 \pm 1.0$ \\
\hline Silk & & $\sim 40$ & $\sim 93$ \\
\hline Chitosan ${ }^{c}$ & & $\sim 35$ & $\sim 80$ \\
\hline Collagen $I^{\mathrm{d}}$ & & $6.31 \pm 0.33$ & $75 \pm 8$ \\
\hline Hyaluronic acid $^{\mathrm{d}}$ & & $1.33 \pm 0.20$ & $80 \pm 01$ \\
\hline Gelatin ${ }^{\mathrm{e}}$ & $801 \pm 108$ & & 97.51 \\
\hline Gelatin ${ }^{\mathrm{f}}$ & $80 \pm 8$ & & $\sim 97$ \\
\hline Silk/CaP & $16,700 \pm 4,500$ & $400 \pm 102$ & Table 1 \\
\hline
\end{tabular}

a Salt-leached SF scaffolds derived from $8 \%$ aqueous silk solution [30].

b Salt-leached SF scaffolds derived from $17 \%$ silk solution dissolved in hexafluoroisopropanol $[46,47]$.

c Freeze-dried scaffold derived from $2 \%$ aqueous solution [48].

${ }^{\mathrm{d}}$ Freeze-dried scaffold derived $1 \%$ aqueous solution [49].

e Scaffold prepared by a combination of thermally induced phase separation and porogen leaching technique [50].

f Commercial gelatin scaffold: Gelfoam ${ }^{\circledR}[50]$.

g Scaffolds prepared by a combination of salt-leaching/freeze-drying approach; the dry state modulus came from Ref. [40].

\section{Conclusions}

This study proposed novel porous bilayered scaffolds, built up by fully integrating a SF layer and a silk-nanoCaP layer, for OCD regeneration. These scaffolds presented superior mechanical properties and suitable stability, as well as spatially controllable porosity and CaP distribution and confinement. The scaffolds supported the attachment, viability and proliferation of RBMSCs in vitro. Additionally, the silk-nanoCaP layer promoted better osteogenesis differentiation of RBMSCs in osteogenic conditions as compared with the silk layer. Furthermore, these scaffolds allowed tissue ingrowth and induced only a very weak foreign body reaction when subcutaneously implanted in rabbit. When implanted in rabbit knee critical OCDs, the bilayered scaffolds were integrated well with the host tissues. Moreover, the bilayered scaffolds supported cartilage regeneration in the top silk layer, and encouraged large amounts of subchondral bone ingrowth and angiogenesis in the bottom silk-nanoCaP layer. Although a long-term in vivo study is necessary, the preliminary in vivo data of the bilayered scaffolds together with their other desirable features confirm that the silk/ silk-nanoCaP bilayered scaffolds are suitable for OCD regeneration.

\section{Conflict of interest}

The authors have no conflicting interests to declare.

\section{Acknowledgments}

This study was funded by the Portuguese Foundation for Science and Technology (FCT) projects Tissue2Tissue (PTDC/CTM/ 105703/2008) and OsteoCart (PTDC/CTM-BPC/115977/2009), as well as the European Union's FP7 Programme under grant agreement no REGPOT-CT2012-316331-POLARIS. The authors are grateful to Viviana P. Ribeiro and Teresa Oliveira for the assistance with the immunohistochemical staining. L-P.Y. was awarded a FCT $\mathrm{PhD}$ scholarship (SFRH/BD/64717/2009). The FCT distinction attributed to J.M.O. under the Investigator FCT program (IF/ 00423/2012) is also greatly acknowledged.

\section{Appendix A. Figures with essential colour discrimination}

Certain figures in this article, particularly Figs. 2, 3, 5, 7-13 are difficult to interpret in black and white. The full colour images can be found in the on-line version, at http://dx.doi.org/10.1016/ j.actbio.2014.10.021.

\section{Appendix B. Supplementary data}

Supplementary data associated with this article can be found, in the online version, at http://dx.doi.org/10.1016/j.actbio.2014.10. 021.

\section{References}

[1] Mano JF, Reis RL. Osteochondral defects: present situation and tissue engineering approaches. J Tissue Eng Regener Med 2007;1:261-73.

[2] Martin I, Miot S, Barbero A, Jakob M, Wendt D. Osteochondral tissue engineering. J Biomech 2007;40:750-65.

[3] Gomoll AH, Madry H, Knutsen G, van Dijk N, Seil R, Brittberg M, et al. The subchondral bone in articular cartilage repair: current problems in the surgical management. Knee Surg Sports Traumatol Arthrosc 2010;18:434-47.

[4] Weil Jr L. Biologics in foot and ankle surgery. Foot Ankle Spec 2011;4:249-52.

[5] Zengerink M, Struijs PA, Tol JL, van Dijk CN. Treatment of osteochondral lesions of the talus: a systematic review. Knee Surg Sports Traumatol Arthrosc 2010;18:238-46.

[6] Bitton R. The economic burden of osteoarthritis. Am J Manag Care 2009; 15:S230-5.

[7] Panseri S, Russo A, Cunha C, Bondi A, Di Martino A, Patella S, et al. Osteochondral tissue engineering approaches for articular cartilage and subchondral bone regeneration. Knee Surg Sports Traumatol Arthrosc 2012:20:1182-91.

[8] Langer R, Vacanti JP. Tissue engineering. Science 1993;260:920-6.

[9] Wang X, Wenk E, Zhang X, Meinel L, Vunjak-Novakovic G, Kaplan DL. Growth factor gradients via microsphere delivery in biopolymer scaffolds for osteochondral tissue engineering. J Control Release 2009;134:81-90.

[10] Shao XX, Hutmacher DW, Ho ST, Goh JC, Lee EH. Evaluation of a hybrid scaffold/cell construct in repair of high-load-bearing osteochondral defects in rabbits. Biomaterials 2006;27:1071-80.

[11] Zhang W, Chen J, Tao J, Hu C, Chen L, Zhao H, et al. The promotion of osteochondral repair by combined intra-articular injection of parathyroid hormone-related protein and implantation of a bi-layer collagen-silk scaffold. Biomaterials 2013;34:6046-57.

[12] Minas T, Gomoll AH, Rosenberger R, Royce RO, Bryant T. Increased failure rate of autologous chondrocyte implantation after previous treatment with marrow stimulation techniques. Am J Sports Med 2009;37:902-8.

[13] O'Shea TM, Miao X. Bilayered scaffolds for osteochondral tissue engineering. Tissue Eng Part B Rev 2008;14:447-64.

[14] Oliveira JM, Rodrigues MT, Silva SS, Malafaya PB, Gomes ME, Viegas CA, et al Novel hydroxyapatite/chitosan bilayered scaffold for osteochondral tissueengineering applications: scaffold design and its performance when seeded with goat bone marrow stromal cells. Biomaterials 2006;27:6123-37.

[15] Reyes R, Delgado A, Sanchez E, Fernandez A, Hernandez A, Evora C. Repair of an osteochondral defect by sustained delivery of BMP-2 or TGF-beta1 from a bilayered alginate-PLGA scaffold. J Tissue Eng Regener Med 2014;8:521-33.

[16] Guo X, Park H, Liu G, Liu W, Cao Y, Tabata Y, et al. In vitro generation of an osteochondral construct using injectable hydrogel composites encapsulating rabbit marrow mesenchymal stem cells. Biomaterials 2009;30:2741-52.

[17] Chen J, Chen H, Li P, Diao H, Zhu S, Dong L, et al. Simultaneous regeneration of articular cartilage and subchondral bone in vivo using MSCs induced by a spatially controlled gene delivery system in bilayered integrated scaffolds. Biomaterials 2011;32:4793-805.

[18] Kim K, Lam J, Lu S, Spicer PP, Lueckgen A, Tabata Y, et al. Osteochondral tissue regeneration using a bilayered composite hydrogel with modulating dual growth factor release kinetics in a rabbit model. J Control Release 2013;168:166-78. 
[19] Mohan N, Dormer NH, Caldwell KL, Key VH, Berkland CJ, Detamore MS. Continuous gradients of material composition and growth factors for effective regeneration of the osteochondral interface. Tissue Eng Part A 2011; 17:2845-55.

[20] Xue D, Zheng O, Zong C, Li Q, Li H, Qian S, et al. Osteochondral repair using porous poly(lactide-co-glycolide)/nano-hydroxyapatite hybrid scaffolds with undifferentiated mesenchymal stem cells in a rat model. J Biomed Mater Res A 2010;94:259-70.

[21] Kon E, Delcogliano M, Filardo G, Busacca M, Di Martino A, Marcacci M. Novel nano-composite multilayered biomaterial for osteochondral regeneration: a pilot clinical trial. Am J Sports Med 2011;39:1180-90.

[22] Joshi N, Reverte-Vinaixa M, Diaz-Ferreiro EW, Dominguez-Oronoz R. Synthetic resorbable scaffolds for the treatment of isolated patellofemoral cartilage defects in young patients: magnetic resonance imaging and clinical evaluation. Am J Sports Med 2012;40:1289-95.

[23] Bedi A, Foo LF, Williams Iii RJ, Potter HG. The maturation of synthetic scaffolds for osteochondral donor sites of the knee: An MRI and T2-mapping analysis. Cartilage 2010;1:20-8.

[24] Moutos FT, Freed LE, Guilak F. A biomimetic three-dimensional woven composite scaffold for functional tissue engineering of cartilage. Nat Mater 2007;6:162-7.

[25] Kon E, Vannini F, Buda R, Filardo G, Cavallo M, Ruffilli A, et al. How to treat osteochondritis dissecans of the knee: surgical techniques and new trends AAOS exhibit selection. J Bone Joint Surg Am 2012;94. e1(1-8).

[26] Yang PJ, Temenoff JS. Engineering orthopedic tissue interfaces. Tissue Eng Part B Rev 2009:15:127-41.

[27] Grayson WL, Chao PH, Marolt D, Kaplan DL, Vunjak-Novakovic G. Engineering custom-designed osteochondral tissue grafts. Trends Biotechno 2008;26:181-9.

[28] Yan LP, Wang YJ, Ren L, Wu G, Caridade SG, Fan JB, et al. Genipin-cross-linked collagen/chitosan biomimetic scaffolds for articular cartilage tissue engineering applications. J Biomed Mater Res A 2010;95A:465-75.

[29] Vepari C, Kaplan DL. Silk as a biomaterial. Prog Polym Sci 2007;32:991-1007.

[30] Kim UJ, Park J, Joo Kim H, Wada M, Kaplan DL. Three-dimensional aqueous-derived biomaterial scaffolds from silk fibroin. Biomaterials 2005;26:2775-85

[31] Oliveira AL, Sun L, Kim HJ, Hu X, Rice W, Kluge J, et al. Aligned silk-based 3-D architectures for contact guidance in tissue engineering. Acta Biomater 2012;8:1530-42.

[32] Correia C, Bhumiratana S, Yan LP, Oliveira AL, Gimble JM, Rockwood D, et al. Development of silk-based scaffolds for tissue engineering of bone from human adipose-derived stem cells. Acta Biomater 2012;8:2483-92.

[33] Kundu B, Kundu SC. Osteogenesis of human stem cells in silk biomaterial for regenerative therapy. Prog Polym Sci 2010;35:1116-27.

[34] Fuchs S, Jiang X, Schmidt H, Dohle E, Ghanaati S, Orth C, et al. Dynamic processes involved in the pre-vascularization of silk fibroin constructs for bone regeneration using outgrowth endothelial cells. Biomaterials 2009;30:1329-38.

[35] Dorozhkin SV, Epple M. Biological and medical significance of calcium phosphates. Angew Chem Int Ed 2002;41:3130-46.

[36] Salgado AJ, Coutinho OP, Reis RL. Bone tissue engineering: state of the art and future trends. Macromol Biosci 2004;4:743-65.

[37] Yan LP, Oliveira JM, Oliveira AL, Caridade SG, Mano JF, Reis RL. Macro/ microporous silk fibroin scaffolds with potential for articular cartilage and meniscus tissue engineering applications. Acta Biomater 2012;8:289-301.
[38] Yan LP, Silva-Correia J, Correia C, Caridade SG, Fernandes EM, Sousa RA, et al. Bioactive macro/micro porous silk fibroin/nano-sized calcium phosphate scaffolds with potential for bone-tissue-engineering applications. Nanomed (London) 2013;8:359-78.

[39] Yan LP, Salgado AJ, Oliveira JM, Oliveira AL, Reis RL. De novo bone formation on macro/microporous silk and silk/nano-sized calcium phosphate scaffolds. J Bioact Compat Polym 2013;28:439-52.

[40] Yan LP, Oliveira JM, Oliveira AL, Reis RL. Silk fibroin/nano-CaP bilayered scaffolds for osteochondral tissue engineering. Key Eng Mater 2014;587:245-8.

[41] Jin HJ, Park J, Karageorgiou V, Kim UJ, Valluzzi R, Cebe P, et al. Water-stable silk films with reduced $\beta$-sheet content. Adv Funct Mater 2005;15:1241-7.

[42] Oliveira JM, Silva SS, Malafaya PB, Rodrigues MT, Kotobuki N, Hirose M, et al. Macroporous hydroxyapatite scaffolds for bone tissue engineering applications: Physicochemical characterization and assessment of rat bone marrow stromal cell viability. J Biomed Mater Res A 2009;91A:175-86.

[43] Oliveira AL, Sampaio SC, Sousa RA, Reis RL. Controlled mineralization of nature-inspired silk fibroin/hydroxyapatite hybrid bioactive scaffolds for bone tissue engineering applications. In: Presented at the 20th European Conference on Biomaterials. Nantes, 27 September-1 October 2006.

[44] Karageorgiou V, Kaplan D. Porosity of 3D biomaterial scaffolds and osteogenesis. Biomaterials 2005;26:5474-91.

[45] Khanarian NT, Jiang J, Wan LQ, Mow VC, Lu HH. A hydrogel-mineral composite scaffold for osteochondral interface tissue engineering. Tissue Eng Part A 2012;18:533-45.

[46] Nazarov R, Jin HJ, Kaplan DL. Porous 3-D scaffolds from regenerated silk fibroin. Biomacromolecules 2004;5:718-26.

[47] Marolt D, Augst A, Freed LE, Vepari C, Fajardo R, Patel N, et al. Bone and cartilage tissue constructs grown using human bone marrow stromal cells, silk scaffolds and rotating bioreactors. Biomaterials 2006;27:6138-49.

[48] Bhardwaj N, Kundu SC. Silk fibroin protein and chitosan polyelectrolyte complex porous scaffolds for tissue engineering applications. Carbohydr Polym 2011;85:325-33.

[49] Wang TW, Spector M. Development of hyaluronic acid-based scaffolds for brain tissue engineering. Acta Biomater 2009;5:2371-84.

[50] Liu X, Smith LA, Hu J, Ma PX. Biomimetic nanofibrous gelatin/apatite composite scaffolds for bone tissue engineering. Biomaterials 2009;30:2252-8

[51] Hutmacher DW. Scaffolds in tissue engineering bone and cartilage. Biomaterials 2000;21:2529-43.

[52] Mandal BB, Grinberg A, Seok Gil E, Panilaitis B, Kaplan DL. High-strength silk protein scaffolds for bone repair. Proc Natl Acad Sci USA 2012;109:7699-704.

[53] Collins AM, Skaer NJV, Gheysens T, Knight D, Bertram C, Roach HI, et al. Bonelike resorbable silk-based scaffolds for load-bearing osteoregenerative applications. Adv Mater 2009;21:75-8.

[54] McMahon LA, O’Brien FJ, Prendergast PJ. Biomechanics and mechanobiology in osteochondral tissues. Regener Med 2008;3:743-59.

[55] Altman GH, Diaz F, Jakuba C, Calabro T, Horan RL, Chen JS, et al. Silk-based biomaterials. Biomaterials 2003;24:401-16.

[56] Oliveira JM, Kotobuki N, Tadokoro M, Hirose M, Mano JF, Reis RL, et al. Ex vivo culturing of stromal cells with dexamethasone-loaded carboxymethylchitosan/poly(amidoamine) dendrimer nanoparticles promotes ectopic bone formation. Bone 2010;46:1424-35.

[57] Zhang Y, Wu C, Friis T, Xiao Y. The osteogenic properties of CaP/silk composite scaffolds. Biomaterials 2010;31:2848-56. 